\title{
FACTORES QUE PROMOCIONAN LA FALTA DE ÉTICA EN LAS PRÁCTICAS DE PRODUCCIÓN Y LOGÍSTICA DE LAS EMPRESAS TRANSNACIONALES
}

\author{
Arturo Luque GonZÁlez \\ Investigador en la Universidad rey Juan Carlos, Departamento de Economía de la Empresa \\ Carmen de Pablos Heredero \\ Directora del Máster Universitario en Organización de Empresas, Universidad Rey Juan Carlos
}

DOI: $10.1387 /$ lan-harremanak. 16578

\section{ABSTRACT}

Este articulo tiene como objetivo fundamental recoger y exponer los factores que promocionan y hacen efectiva la producción textil internacional dentro de un marco de falta de ética y asimetría normativa. En la realidad económica que impera actualmente, se entiende necesaria la clarificación de elementos y procesos irradiadores que facilitan de manera inexorable la capilaridad e interconexión de actores que facilitan la producción textil, tanto desde infimos talleres en lugares recónditos hasta lugares más cercanos y conocidos como son los centros de decisión y poder. El artículo reflexiona sobre aspectos que afectan a las malas prácticas en los procesos de fabricación textil pero que a su vez no se pueden solucionar únicamente desde las escuelas de negocios o corrientes institucionalizadas. Se evidencia la posibilidad de crear valor, siendo ético — al menos según la legislación vigente- a la vez que se pueden promocionar sistemas de producción alejados de toda moral y deshumanizados, pero bendecidos por buena parte de la sociedad como asi reflejan los volumenes de ventas. El trabajo concluye con de una serie de reflexiones sobre la necesidad de desarrollar investigaciones futuras para ahondar sobremanera en el papel que han de tener las 
organizaciones internacionales si no cumplen su cometido, por acción u omisión, así como los tipos de acciones correctoras posibles cuando las propias empresas transnacionales gravitan alrededor de los circulos de poder.

Palabras clave: globalización, responsabilidad social corporativa, empresas transnacionales, corrupción, legislación.

The main purpose of this article is to collect and present the factors that promote and affect the international textile production in a framework characterized by unethical and regulatory asymmetries. The economic situation that currently prevails, the clarification of elements and processes that facilitate the interconnection of actors that make textile production possible is required, from tiny workshops located in remote countries, to places nearby of powerful centres for the decision making. The article reflects on issues affecting poor practices in textile manufacturing processes, which cannot be solved solely from business schools or institutionalized currents. The possibility of creating value by being ethical, is evident, —at least according to the law - while that may promote production systems away from any moral and dehumanized but blessed by much of society, as sales volumes reflect. This document of research concludes through a series of reflections about the need to develop future research to deepen on the role that international organizations have, when they discharge their responsibilities either by action or omission, as well as the types of possible corrective actions when the transnational corporations gravitate around the circles of power.

Keywords: globalization, corporate social responsibility, transnational companies, corruption, legislation. 


\section{Introducción}

Las empresas transnacionales (en adelante ET) textiles están modificando la manera de comprar por parte de los consumidores (oferta de productos $^{1}$, posibilidad de compra online, precio, envío gratuito, etc.), a la vez que han evolucionado sus sistemas de producción (Sojo Calvo, 2012) (Su, 2013) a través de sofisticados métodos tecnológicos de control de la producción (Hwang \& Seruga, 2011), innovación y deslocalizaciones (Werner y Weiss, 2006: 111). Las ET se relacionan al máximo nivel ${ }^{2}$ entre países y mercados (Maak, 2009: 361-372) con eficientes sistemas de diplomacia y lobbies que les facilitan su trabajo. Han afinado el uso y adquisición de recursos necesarios (Kumar y Arbi, 2008; Bruce y Daly, 2011; Macarthy y Jayarathre, 2012), como son las materias primas, energía y personal, tan necesarios para la producción en la industria textil; todo ello unido a un estricto desarrollo de las relaciones entre todos los grupos de interés que conforman las multinacionales textiles tanto de manera endógena como exógena, siendo estas necesarias para elaborar grandes volúmenes de prendas textiles ${ }^{3}$, a bajo coste en muchos casos, como sucede en los países subdesarrollados o en vías de desarrollo, véase Bangladesh, Camboya o India - a modo de ejemplo - donde se encuentra gran parte de su producción deslocalizada a través de talleres textiles. En ocasiones, se producen prácticas deshumanizantes tal y como señala Human Rights Watch (2015), los mayores abusos tienen lugar en fábricas pequeñas subcontratadas que quedan al margen de los controles que establece el sistema. Según Ditty (2015)

\footnotetext{
1 «Ropa inteligente: el futuro de la tecnología textil» a través de la publicación Universia del 26/06/2015 disponible en http://noticias.universia.es/cultura/noticia/2015/06/26/1127310/ropa-inteligente-futurotecnologia-textil.html\#

2 «Pablo Isla no da puntada sin hilo en China: El presidente de Inditex se reúne con miembros del gobierno del gigante asiático en su visita a un mercado clave para su compañía, señalando que mantuvo "[...] un encuentro institucional con el ministro de Protección Medioambiental de la República de China, Chen Ji Ning, al que le presentó el plan de sostenibilidad que el grupo está implantando en todo el mundo", información elaborada por S. Vázquez a través de La voz de Galicia del 29/10/2015 disponible en http:/www.lavozdegalicia.es/noticia/ economia/2015/10/29/pablo-isla-da-puntada-hilo-china/00031446136621114241102.htm

3 Ver informe de la OMC, Estadísticas del comercio internacional 2015 (comercio de mercancías), disponible en https://www.wto.org/spanish/res_s/statis_s/its2015_s/its15_toc_s.htm
} 
Hoy, el sector textil y de confección de la Comunidad Europea sigue siendo una industria basada en las PYME. Las empresas de menos de 50 trabajadores representan más del $90 \%$ de la fuerza de trabajo y producen casi el $60 \%$ del valor agregado. La confección de ropa y textiles, es también una de las industrias más globalizadas con complejas cadenas de producción, al por mayor y al por menor, donde es común encontrar que un solo producto vincula a decenas de grupos de interés en muchos continentes.

La fuerza laboral depende de la demanda (pedidos). Significa que si hay más encargos se contrata más personal y viceversa (circunstancia no exclusiva de países subdesarrollados o en vías de desarrollo). Esto es razonable, salvo cuando la obsesión por el ahorro de costes genera una transgresión de aspectos éticos y morales que se refleja en formas de contratación y condiciones laborales deshumanizantes (Human Rights Watch, 2015), acompañadas de formas de producción medioambientalmente insostenibles (Naredo, 1999).

Estas situaciones han influido per se en el cambio de modelo de relaciones comerciales, sociales y sindicales a través de acuerdos de libre comercio o acuerdos bilaterales ${ }^{4}$ que impulsan legislaciones más favorables para el posterior aprovechamiento de las mismas, lo que genera una potenciación del comercio internacional, así como una desactivación paralela de las relaciones sindicales, evidenciando la precariedad laboral y, por tanto, dejando de existir un elemento más de equilibrio social, como así señala el informe titulado Flawed Fabrics (tejidos defectuosos) con fecha de octubre del 2014 elaborado por el Centre for Research on Multinational Corporations ${ }^{5}$ de Holanda, en el que además se señalan graves violaciones de los derechos humanos y laborales dentro del sector textil.

Esta situación está conectada con la reputación empresarial, la relación que tiene la empresa con su cadena de valor, así como con todo lo que gravita sobre la misma, incluyendo el medio ambiente y a todos los seres vivos y ecosistemas que son afectados por la acción directa de los seres humanos a lo largo de la actividad industrial.

Se ponen de relieve aspectos inseparables y consustanciales a toda actividad industrial como son la ética, las relaciones de poder y/o legislaciones a medida. Dentro de un marco de avance continuo como son los procesos de mundialización, se ha institucionalizado como leit motiv el «trabaja rápido y dame un buen

\footnotetext{
4 "China ha entrado en varios Acuerdos de Libre Comercio (ALC) sobre bases bilaterales y multilaterales. Estos han tenido un impacto significativo en la región geográfica asiática, y han resultado de gran influencia para alentar la dirección de los flujos comerciales y del desarrollo de cadenas de suministro" Información elaborada por Chris Devonshire-Ellis a través de China-briefing del 01/02/2015, disponible en http://www.china-briefing.com/ news/2015/02/01/entendiendo-los-acuerdos-bilaterales-y-multilaterales-de-china.html

5 Flawed fabrics: The abuse of girls and women workers in the South Indian textile industry, 10/2014, disponible en http://www.somo.nl/publications-en/Publication_4110
} 
precio ya que si no otra empresa o país lo hará». Esta situación choca con la actitud de los propios consumidores a la hora de demandar productos más saludables, fabricados de una manera más ética y sostenible, aunque con un poder limitado.

El concepto de responsabilidad social empresarial o corporativa (RSE o RSC) es un concepto "voluntario», entendiéndose como todo aquello a lo que no obliga la ley. Su razón de ser se justifica por un mayor control y divulgación de todo lo concerniente a aspectos sociales, medioambientales, éticos o conductuales en los diferentes grupos de interés que la componen, tanto directivos y empleados así como consumidores/usuarios y proveedores. Este concepto anima a que las organizaciones desarrollen prácticas sostenibles y con efectos positivos en las sociedades donde operan. Todo ello implícitamente irradiado por las diferentes connotaciones culturales, sociales, ideológicas o religiosas de cada lugar (Francés, 2005; García, 2012; Matten y Moon, 2008). El concepto de responsabilidad social corporativa, no deja de desarrollarse y crecer con el paso del tiempo, tanto por el volumen de contingencias que abarca, así como por el número de empresas y sectores a los que afecta, tal y como señala el informe Forética (2015) sobre el estado de la Responsabilidad Social de las Empresas en España. Según Schneider (2011)

De acuerdo a recientes estudios realizados por KPMG, en Espańa y en Chile, y en oposición a lo vaticinado por el Financial Times a finales de 2008 de que la RSE era una moda empresarial pasajera, en el caso de los empresarios espańoles, un $75 \%$ manifestó que el interés y las inversiones en RSE se mantienen, aún en un escenario de crisis. En Chile, un 42\% manifiesta que el interés aumenta, mientras que un 75\% indica que las inversiones en RSE en sus respectivas empresas no van a percibir cambios.

La demanda social de RSC hace que deba aumentar, en mayor o menor medida, la necesidad de adaptar el propio concepto de RSC hacia posiciones más éticas y realistas, teniendo, a su vez, muy presentes los contextos políticos, geográficos, económicos, culturales, medioambientales, religiosos y sociales que existen en los lugares donde se desarrolla la actividad. Las legislaciones de los principales países productores de textil son extremadamente locales y, como se ha indicado previamente, las acciones de responsabilidad social corporativa son excluyentes de los contextos legales. Tal y como señalaban Farhoomand y Lovelock (2001), aunque el comercio es global, las legislaciones siguen siendo locales y esto no ha variado en gran medida.

6 "Los consumidores más jóvenes respaldan la alimentación saludable y están dispuestos a pagar más por ella» a través del Informe sobre salud y bienestar We Are What We Eat de la consultora Nielsen del 20/01/2015, disponibles en http://www.nielsen.com/eu/es/insights/news/2015/younger-consumers-endorse-healthy-foodswith-a-willingness-to-pay-a-premium.html y http://www.nielsen.com/us/en/insights/reports/2015/we-arewhat-we-eat.html respectivamente. 
La responsabilidad social corporativa ha ido evolucionando desde posiciones liberales, como la del economista Friedman $(1966)^{7}$, hasta otras más críticas o versiones contrapuestas que han puesto de relieve diferentes autores como Mulligan (1986), Bowie (1991), Grant (1991), Frederick (1994), Lee y NcKenzie (1994), Lozano (1999), Ostas (2001), McAleer (2003), Gallager (2005), Torres (2006), Cosans (2009) y Anguita (2010). Estas posiciones se han ido moderando hasta llegar a comprender que un comportamiento responsable no debería ser incompatible con la creación de valor, ya que la aplicación de la RSC en términos positivos y sin intereses particulares mejora la calidad de la empresa, tanto en el entorno que la rodea, así como reduciendo los riesgos y aumentando su reputación. Sin olvidar que la RSC no debe de sustituir a una legislación existente o a la que debería de existir en caso de ausencia de la misma.

La RSC es, por tanto, un elemento importante para las empresas, quienes, además de relacionarla de manera directa con la misión y visión de la compañía, lo asocian a lo que la sociedad a través de sus actos esperan de ellas (Rojas et al., 2006; Costa, 2007; y Barroso, 2008a y 2008b).

Es importante diferenciar lo que una empresa tiene que hacer, o a lo que le obliga la ley, y lo que realmente debería hacer, ya que podemos encontrarnos con situaciones como las que describe Ordaz (2014)

¿Salud o trabajo?, les plantearon durante años, y ellos se creyeron que no había otra alternativa, y entre el peligro de una enfermedad probable y el hambre inmediata de sus hijos, eligieron seguir trabajando en la gran fábrica de acero instalada al costado de sus casas.

Los contextos donde las empresas operan a veces promocionan falta de coherencia, lo que se materializa en que una empresa ejerce su responsabilidad de una manera u otra en relación al territorio y legislación en la que opera, incluso cuando su código deontológico así como su RSC no es lo que indican.

Podemos afirmar que la RSC supone un compromiso semivoluntario relacionado directamente con un comportamiento ético y responsable, pero, ¿realmente es voluntario? "[...] de hecho, los consumidores votan con sus chequeras si sienten que las transnacionales no actúan en favor de la salud pública, los derechos de los trabajadores y el medio ambiente[...]» (Holt et al., 2004: 6), o el poder del consumidor organización no gubernamental o medio de comunicación ha hecho que se condicione la conducta de los usuarios hasta el punto de dejar de consumir un producto o generar un debate condicionado con capacidad de pervertir actitudes empresariales, según Eberhardt y Olivet (2012: 9)

7 "The social responsibility of business is to increase its profits", texto elaborado por Milton Friedman y publicado a través de New York Times Magazine el 13/1970. 
Los abogados especializados en inversiones mantienen un firme control del discurso académico sobre legislación en materia de inversiones y arbitraje, dado que generan una gran parte de los escritos académicos sobre este tema, ocupan en promedio el $74 \%$ de las juntas editoriales de las principales revistas especializadas en derecho de inversiones.

Sin olvidar, como indican Folkes y Kammis (1999), Luchs et al. (2010) y White (2012), que el consumo responsable no sustituye la calidad del producto que se adquiere y tampoco una calidad superior del mismo compensa el tener comportamientos no éticos. De hecho, usuarios y consumidores están empezando a incluir cuestiones éticas en sus evaluaciones de productos y servicios, lo que podría entenderse como un contrapoder atacando desde su base a la globalización (Barnett et al., 2005; Conroy, 2007).

De manera cuantitativa es complejo precisar lo que "gana» una empresa responsable, aunque existen proyectos europeos como CSR-IMPACT (www.csrimpact.eu), que tienen como objetivo desarrollar mecanismos que permiten medir el retorno de imagen en términos cuantitativos, cosa que, pese a observar que es positivo, sigue siendo difícil de tecnificar, ya que la mayoría de las compañías, en definitiva, viven de su reputación o de su producto, aunque existen diferentes autores, procedimientos y herramientas como las propuestas por Global Reporting Initiative (2006) a través de indicadores G3 (Vintró, 2010) o trabajos al respecto, como el de Weber (2008), como herramientas de aproximación y medida de RSC.

Una empresa que actúa de manera responsable tiene mejores beneficios internos y externos ${ }^{8}$, pero una conducta poco responsable 9 , poco ética o en definitiva alejada de los cánones de solidaridad instaurados en la sociedad, podría

8 Schaltegger y Burrit, en el año 2005, muestran en un estudio algunos beneficios empresariales de la responsabilidad social corporativa como es la gestión de riesgos, la reducción de costes, mejora de la reputación y el valor de marca.

- Heal en el año 2005, también menciona en su investigación teórica a la gestión de riesgos y la mejora del valor de marca, y añadía otros beneficios como una mejor relación con los reguladores y una mayor productividad de los empleados.

- Epstein y Roy en el año 2001, en un estudio cuantitativo y cualitativo descubrieron que la responsabilidad social corporativa ayudaba a evitar la mala publicidad en la prensa, boicots de los clientes e influencias del mercado negativas, mayor motivación de los empleados, mejor acceso al capital y crecimiento en el mercado de valores.

- Existen herramientas proporcionadas en estas tres empresas para medir el retorno social sobre inversión www.sroiuk.org. www.sroicanada.ca o www.thesroinetwork.org/argentina (creada a finales de 2011).

9 Un ejemplo de conducta poco responsable podría ser la gestión por parte de Sacyr en relación a las obras del canal de Panamá en un artículo titulado «La picaresca de Sacyr se ahoga en el canal de Panamá» señalando "Pero estas cosas no se ventilan en público, no se airean, porque el daño reputacional para la firma es brutal y, por ende, para todo el sector de la obra pública y de la ingeniería española», texto elaborado por J. Cacho a través de Vozpopuli.com del 5/01/2014 
generar pérdidas incalculables hasta llegar a destruir verdaderos emporios empresariales, como en el caso de determinadas empresas de hidrocarburos, químicas o textiles (catástrofes como la de Exxon Valdez ${ }^{10}$, la planta química textil de Linjiang en China ${ }^{11}$ o el siniestro en Bangladesh de Rana Plaza ${ }^{12}$ ).

La sociedad avanza hacia el ¿¿cómo?, y no solo el ¿qué?, o el ¿cuánto? Cada día queremos conocer más sobre cómo se elaboran los productos que consumimos, en qué condiciones se han creado, qué tipo de normativas cumplen, si han seguido únicamente las recomendaciones mínimas obligatorias, si la empresa ha ido más allá y ha instaurado determinado modelo productivo sin ningún tipo de seguridad, higiene y control o si realmente presenta un modelo en sintonía con lo que la sociedad les reclama.

Estas necesidades de seguridad, higiene y control pueden poner en tela de juicio muchas teorías pasadas como las de Milton Friedman, centrada en hacer todo lo posible para incrementar los beneficios siempre que se cumpla con la ley y no se cometa fraude, o las de Porter y Kramer (2011), relacionadas principalmente con hacer el bien a través de una conexión filantrópica, pero ¿qué ocurre cuando no existe ley o esta se hace a medida? En estos casos se puede dar la posibilidad de que exista una falta de control organizativo a favor de determinadas instituciones (públicas o privadas), debilitamiento institucional, existencia o creación de grupos de interés y poderes fácticos, así como un posible aumento de riesgos de todo tipo — químico, legislativo, social, migratorio- que generen una minimización de derechos sociales - y derechos de la persona-.

El objetivo de este artículo consiste en conocer los factores que promocionan la falta de ética en las prácticas de producción y logística de las empresas transnacionales textiles, analizando su relación con buenas o malas prácticas empresariales, a la vez que intenta descifrar muchas de las fuerzas que irradian sobre determinadas propuestas empresariales y órganos legislativos.

Los factores identificados se explicarán a continuación teniendo en cuenta condicionantes en muchos de los casos no previstos, como son el cambio climático o las migraciones, pero siendo determinantes a la hora de realizar una actividad empresarial con éxito en todas y cada una de las fases y aristas de este poliédrico engranaje de la empresa textil.

10 «La marca BP castigada» texto de Julián Ballesteros a través de Value4Chain del 5/02/2014, disponible en http://value4chain.com/tag/exxon-valdez/.

11 "Greenpeace denuncia los vertidos del sector textil chino, con maniquies» texto de la Vanguardia del 4/12/2012, disponible en http://www.lavanguardia.com/vida/20121204/54356083848/greenpeace-denunciavertidos-del-sector-textil-chino.html.

12 «El precio social de la ropa», noticia del diario El País del 5/05/2013 realizada por N. Galarraga disponible en http://internacional.elpais.com/internacional/2013/05/03/actualidad/1367605262_019387.html 


\section{Factores que influyen en que se den comportamientos deshumanizantes}

Más allá de entender que no todos los factores inciden por igual dentro de la pirámide textil, a continuación identificamos cada uno de ellos, junto con su análisis teniendo en cuenta que la situación que describimos de los mismos en este mismo instante, quedará en muchos casos obsoleta acto seguido de finalizar este párrafo debido a la velocidad y adaptación de este tipo de superestructuras.

\subsection{Globalización}

La integración de los sistemas de comunicación de todo tipo, la automatización de la información, redes de satélites, Internet ${ }^{13}$, la expansión de empresas transnacionales, etc., ha hecho posible la libre circulación de producción textil así como de capitales aunque de manera desigual. Para Beck (1998: 29)

La globalización significa los procesos en virtud de los cuales los Estados nacionales soberanos se entremezclan e imbrican mediante actores transnacionales y sus respectivas probabilidades de poder, orientaciones, identidades y entramados varios. El concepto de globalización se puede describir como un proceso, que crea vínculos y espacios sociales transnacionales, revaloriza culturas locales y trae a un primer plano terceras culturas...

De manera paralela, o mejor dicho simbiótica, existe un ejército de millones de inversores dispuestos a invertir en cualquier sector, por mínima que sea la oportunidad de negocio, a la velocidad de un simple clic de ratón. Por eso, continuamente se están desarrollando nuevos bienes y servicios capaces de satisfacer o generar nuevas necesidades a la vez que se generan oportunidades.

La globalización ${ }^{14}$ gestiona parte de los intereses públicos y sociales hacia un interés privado con una teoría darwiniana a nivel empresarial, para Iglesias (2015: 3)

13 "En la era de Internet, el control del Estado alcanza dimensiones alucinantes, ya que, de una manera o de otra, como ya se ha dicho, confiamos a Internet nuestros pensamientos más personales e intimos, tanto profesionales como emocionales. Así, cuando el Estado, con ayuda de tecnologías súper poderosas, decide pasar a escanear nuestro uso de Internet, no sólo rebasa sus funciones, sino que, además, profana nuestra intimidad, deshuesa literalmente nuestro espiritu y saquea el refugio de nuestra vida privada», noticia elaborada por I. Ramonet a través del editorial de Le Monde Diplomatique del N.o240 del 10/2015.

14 Existen centenares de trabajos y teorías sobre globalización, entre ellas las de Octavio Lanni, Anthony Guiddens, Chakravarthi Raghavan, Ulrich Beck, Pablo Raúl Fernández Llerena, John Kenneth Galbraith, Milton Friedman, Johan Norberg, Jeffrey Sachs, J. Ziegler, N. Chomsky, J. M. Pureza, etc.

- "Desigualdad, subdesarrollo y pobreza en la actual globalización ultraliberal» texto de Anastasio Ovejero Bernal, publicación en revista de filosofía de 18/05/2008, disponible en http:// revistadefilosofia.com/18-08.pdf. 
Las tendencias globalizadoras del mundo moderno tienen un enorme potencial de beneficios para la humanidad pero también acarrean los peligros de enfrentamientos y conflictos por sus perversos impactos sobre personas y sobre Estados, y solamente nuestros valores, tradiciones y culturas nos permitirán navegar en ese agitado mar.

\subsection{Libre circulación de capitales}

En la actualidad hay una gran accesibilidad y predisposición a la hora de implantar un modelo financiero e industrial basado en la libre circulación de capitales en países con deficiencias estructurales o limitados democráticamente como en los que se desarrolla la producción textil. A modo de ejemplo «La UE amenazó a Ecuador con eliminar ayudas al desarrollo si no aceptaba el libre comercio» (Eldiario, 2014), mientras que paralelamente Obama acelera las negociaciones del tratado de libre comercio del Pacífico (TPP) (Elpaís, 2015)

En el plano comercial, EE.UU. quiere que países como Vietnam reduzcan su importación de productos textiles chinos para abrir mercado al textil norteamericano (una industria de 250.000 empleos y 20.000 millones de dólares) y mexicano. El objetivo final del TPP es lograr un acuerdo en la región que más crece del mundo en el que quede limitada la influencia económica de China.

Sería positivo intentar llegar a un modelo más coherente y equitativo, ya que existe la libre circulación de capitales, pero no de personas. Este es uno de los muchos resquicios legales que aprovecha la alargada sombra de la globalización en beneficio propio (Vidal y Estefanía, 2002; Aas, 2013), como es el caso de la producción textil. El modelo de sociedad y economía actual lleva consigo una ecuación desigual para todos los ciudadanos del planeta $\mathrm{y}$, en concreto, con los diferentes países en vías de desarrollo que, muchas veces, quedan esquilma$\operatorname{dos}^{15}$ a nivel medioambiental y sobre todo con poco equilibrio social. Para Beck

— «Gobierno y globalización», texto de Jeffrey D. Sachs en el diario El País del 16/10/2011, disponible en http://elpais.com/diario/2011/10/16/negocio/1318770869_850215.html.

— «La globalización: ¿Amenaza u oportunidad?» texto preparado por personal del FMI año 2000, disponible en http://www.imf.org/external/np/exr/ib/2000/esl/041200s.htm.

- «La globalización incrementa la pobreza al mundo?» éxito de bancomundial.org, disponible en http://www.bancomundial.org/temas/globalizacion/cuestiones2.htm.

15 Entrevista al padre jesuita espańol Francisco de Paula Oliva en el humilde barrio de Asunción donde vive titulada ' $L a$ voz de los empobrecidos', donde responde a diferentes cuestiones como "¿Qué papel juegan las compañias agrarias multinacionales en ese reparto desigual?», "Un papel decisivo y siniestro. Aqui operan corporaciones extranjeras cuyos presupuestos anuales son mayores que el presupuesto nacional paraguayo. Figúrese entonces como juegan con nosotros esas empresas multinacionales tan poderosas. Se están haciendo los amos de Paraguay, apoderándose sin escrúpulos de las tierras de los campesinos y destruyendo los cultivos tradicionales para plantar soja destinada a la exportación. Una vergüenza. Estancias de 100.000 hectáreas han caído en manos de compañias extranjeras, norteamericanas o alemanas, tras despojar a los indígenas. Es como una segunda colonización y haría falta lograr una segunda independencia», reportaje desarrollado por Vicente Romero y Miguel Romero a través del diario Elmundo del $30 / 07 / 2014$ 
(1998: 19) "Las empresas pueden producir en un pais, pagar impuestos en otro y exigir gastos estatales en forma de creación de infraestructuras en un tercer pais", circunstancia que es aprovechada por las grandes multinacionales textiles.

\subsection{Empresas transnacionales}

Una ET es aquella que posee filiales ${ }^{16}$ en países diferentes a los de la empresa matriz ${ }^{17}$, desarrollando a su vez influencia ${ }^{18}$ a nivel económico, social, diplomático, comercial, institucional, legal o político (entre muchos otros aspectos) para producir sus bienes o prestar servicios. Además, deberá poseer al menos el $10 \%{ }^{19}$ del capital de la empresa matriz en una filial ${ }^{20}$ extranjera. Según Robbins y Syobaugh (1973), el término comprende cualquier empresa con vínculos en el extranjero. Según De Jong (1973: 135-136) se define como «aquella empresa que realiza sus transacciones en paises extranjeros de la misma manera que interiormente y que utiliza sus medios disponibles sin tener en cuenta las fronteras nacionales». Para Verge y Dufour (2002: 28-35) las ET tienen múltiples implantaciones territoriales, pero cuentan con un único centro de decisión y según la Organización Internacional del Trabajo (2005) gestionan el 3,7\% de mano de obra directa, pero tienen capacidad para influir en el conjunto de la producción mundial.

La empresa transnacional suele operar mediante filiales independientes (de hecho pueden ser un clon de la empresa matriz y, en muchos de los casos, incluso resultado de una adquisición de una empresa que ya existe) con el consiguiente beneficio de crear cortafuegos (o departamentos estancos) tanto en casos de ganancia como de pérdidas, evitando la afectación al resto de filiales o empresa matriz. Además, más allá de tener una oficina corporativa, se permite que cada filial desarrolle diferentes procesos como RRHH, finanzas, etc. Sus

16 El concepto de «filial» para Naciones Unidas (1973: 4) se define como una empresa de derecho local en el país de destino, bajo control efectivo de una matriz ubicada en el país de origen.

17 Entendiéndose como empresa matriz a aquella que controla por lo menos una filial en el extranjero. "The Global Political Economy, Perspectives: Problems And Policies» texto elaborado por Stephen Gill y David Law a través de Baltimore: The Johns Hopkins University Press, pag.191 de 1998; La multinacional transnacional IBM opera en más de 130 países y utiliza más de 30 lenguas diferentes.

18 El futuro según Google: más robots y menos coches, Larry Page y Sergey Brin, sus fundadores, abogan por simplificar la legislación para cumplir su sueño futurista» noticia de Rosa Jiménez Cano a través del diario El País del 08/07/2014, disponible en http://tecnologia.elpais.com/ tecnologia/2014/07/08/actualidad/1404795601_892489.html.

19 Definido por El Departamento de Comercio de Estados Unidos en 1985, pags.2 y 3, aunque hay disparidad según el país.

20 "Como compiten las marcas globales", donde se afirma "Si L'oreal va a crear un mito sobre belleza, debe hacerlo desde un punto de vista particularmente francés. Por lo tanto, las transnacionales harían bien en gestionar sus identidades nacionales asi como su globalidad», texto elaborado por Douglas B. Holt, John A. Quelch y Earl L. Tylor a través de la publicación Harvard Deusto Business Review, V.82, N.o 9, 2004, págs. 48-56. 
ofertas no están coordinadas, se centran en cubrir las necesidades del mercado local, siendo generalmente muy activas en los sectores económicos que presentan mayor dinamismo. En relación a esto, según un estudio de Nielsen ${ }^{21}$ sobre qué países son los que logran menos confianza para la ubicación de una sede, "Aproximadamente dos de cada 10 élites de opinión afirman que se mostrarian menos favorables hacia una empresa si su sede estuviera localizada en China, Arabia Saudi e India (24\%, 22\% y 19\%, respectivamente)" lo que implica el riesgo de fabricar en cualquier parte del mundo con la posibilidad de ensamblar - o poner el made in EU - en países donde la percepción hacia la calidad, prestigio, marca o trato de empleados/entorno es mayor, al igual que se fomenta una invisibilidad para muchos de los consumidores, al carecer el etiquetado de las prendas del recorrido de la cadena de producción en todas sus fases de producción o elaboración.

El sistema de valor en el sector textil está altamente desintegrado (existen transnacionales textiles con más de 7.000 proveedores ${ }^{22}$ ). De hecho, muchas de las multinacionales textiles que en el pasado fabricaban sus productos han evolucionado su concepto diseñando sus propios productos, participando activamente en su distribución para posteriormente venderlos en cualquier parte del planeta, incluso renovando colecciones completas en muchas de sus tiendas cada quince días, aunque estén a miles y miles de kilómetros de su base logística.

Realmente no hay herramientas internacionales capaces de regular un determinado comportamiento responsable, globalmente hablando, por parte de las grandes corporaciones, porque muchas de ellas centradas en maximizar beneficios utilizando cualquier tipo de técnica legal o si no creada a medida por tiralíneas de la legalidad. Para Spendeler (2015) «Una empresa cuyo único fin es ganar dinero para poder dar beneficios a sus inversores no puede preocuparse por lo social $y$ ambiental si no es porque hay un interés comercial detrás", de ahí que una de las medidas correctoras, como señala Meeran (2015), pueda ser el establecimiento de la inversión de la carga de la prueba como instrumento probatorio, para así permitir el acceso a los documentos internos de la empresa y que nos ayuden a clarificar los vínculos reales entre las empresas y sus filiales en caso de abuso o comisión de cualquier ilícito. Para Zabalo (2006), las empresas transnacionales generan una situación de proporcionalidad entre el poder que ejercen (tanto político, como a través de su actividad y por tanto económico) y la impunidad con

21 «En lo que se refiere a la reputación corporativa... ubicación, ubicación, ubicación» elaborado por la consultora Nielsen el 15/04/2015, disponible en http://www.nielsen.com/eu/es/insights/news/2015/when-itcomes-to-corporate-reputation-location-location-location.html.

22 Según la noticia titulada Pablo Isla: "Hemos tenido un año de crecimiento sólido en España" se señala que la compañía textil Inditex "[...] tiene en España 7.000 proveedores que han facturado 4.000 millones de euros, frente a los 6.500 proveedores de 2013, que facturaron 3.500 millones. "Esto ha sido posible gracias al crecimiento de la empresa» ha señalado». Noticia elaborada por Cristina Delgado a través del diario Elpaís.com del $18 / 03 / 2015$. 
la que se mueven. Como señalan Pearce y Toombs (1998), varias naciones subdesarrolladas han impuesto pocas regulaciones a los negocios de las multinacionales a la hora de utilizar materiales peligroso ${ }^{23}$ o emisiones tóxicas con la esperanza de atraer inversiones extranjeras y lograr acceso al know-how tecnológico y científico. Por ello la regulación de la especulación dentro del sistema financiero además de ser necesaria, debe ir más allá, como señalan Rodil y Menezes (2012: 222-223)

[...] resulta más razonable pensar que fue el sistema financiero débilmente regulado, fundamentado en la hipótesis de eficiencia de los mercados, defendidos por el modelo neoliberal en las últimas décadas, el factor determinante de esta crisis financiera.

Aunque esta circunstancia no es única del sistema financiero ni textil. En una reciente entrevista al premio Nobel de Medicina (Harold Varmus, 2015) preguntado sobre la regulación de los fármacos señaló que «El mercado no se regula bien a si mismo, en particular sobre fármacos para enfermedades mortales».

\subsection{Corrupción}

Según Malen (2002: 173-209), la fabricación, distribución y uso de elementos tóxicos (necesarios en muchos casos para la fabricación de prendas textiles) en países pobres suele estar acompañada de prácticas corruptas. Estas prácticas merecen un análisis propio a través de otro documento de investigación, pero no por ello pueden dejarse de señalar debido a que son un elemento unificador de comunidades (aun siendo prácticas deleznables). La corrupción puede resultar, en muchos campos dentro del engranaje textil, en la negación de contratos a los trabajadores sabedores de que no hay ningún tipo de control administrativo ni punitivo. El soborno a funcionarios para desarrollar la actividad productiva (licencias, inspecciones), la presión (Blowfield y Murray, 2008; Escalonilla, 2010; Human Rights Watch, 2015) a los talleres subcontratados para reducir los precios de cada prenda aun sabiendo que prácticamente no cubren gastos o pueden afectar directamente a derechos fundamentales (Anaya, 2012), firmando códigos de conducta que no tienen posibilidad ni medios de cumplir (Locke,

23 «La mayoría de los problemas de la industria de colorantes se encuentran en el sur de Asia, un centro global de producción textil; sin embargo, la industria de los colorantes es global en cuanto a escala y se distribuye en muchos países diferentes. Las plantas de tintes pueden variar desde pequeńas e informales a grandes y organizadas, en la India, por ejemplo, se estima que serán alrededor de 1.000 entidades de pequeña escala y 50 grandes plantas industriales. Mientras que la industria del tinte organizada domina el mercado, hay muchas plantas no organizadas de pequeńa escala que desproporcionadamente se suman al problema de la contaminación" texto elaborado por Worstpolluted sobre los problemas tóxicos (top ten) de contaminación del año 2012, disponible en http://www.worstpolluted.org/projects_reports/display/105.

— «El futuro de la India Tintes y colorantes intermedios» texto elaborado por V.P Mangal a través de Fibre2Fashion.com del 08/2010, disponible en http://www.fibre2fashion.com/industryarticle/29/2887/the-future-of-indian-dyes-and-dye-intermediates1.asp. 
2013) o desarrollando actividad industrial en países afines muchos de ellos a través de prebendas inconfesables Navarro (2013) o legislaciones a medida (Ramonet, 2001; Giner, 2008; y Ziegler, 2013).

Cabe preguntarse de qué depende que un país se comprometa y acepte los convenios de la Organización Internacional del Trabajo, OIT. Evidentemente de las inversiones. Si el país generalmente es subdesarrollado o en vías de desarrollo y los va suscribiendo - mejorando las condiciones de sus trabajadores-, es probable que las inversiones de las empresas textiles vuelen hacia otros países con menos obligaciones como señala el Informe Sobre Las Inversiones en el Mundo (Conferencia de Naciones Unidas UNCTAD, 2013: 9). En él se indica como la mayoría de los gobiernos desean atraer y facilitar la inversión extranjera como medio para fomentar la capacidad productiva y alcanzar un desarrollo sostenible aunque quizás se atraiga algo diferente, como señala el experto profesor y humanista Beck (1998: 17)

Las paradojas políticas y sociales de una economía transnacional, que con la «eliminación de las trabas a la inversión» (es decir, con la eliminación de la normativa ecológica, sindical, asistencial y fiscal) debe ser mimada y premiada para que destruya cada vez más trabajo y de este modo se incrementen cada vez más la producción y los beneficios, deben quedar no obstante científicamente evidenciadas y políticamente reforzadas.

El poder económico e influencia de determinadas empresas, o la acentuación de procesos paralelos a la legalidad, como es el de la corrupción, aumentan en muchos de casos las situaciones de vulnerabilidad (Atondo, 2009). En este sentido, la mala articulación de la norma o práctica haciendo que la misma se aplique de manera diferente según quien lo haga (Fajnzylber, 2006), así como su transparencia: según Nieto de Alba (1994), a menor de la misma, mayor probabilidad de corrupción, hará posible un cambio de paradigma ético y moral.

A modo de ejemplo, el análisis de Bannenberg y Chaupensteiner (2004) indica que la corrupción en Alemania no puede separarse de los procesos de globalización, y pone especial énfasis a los países subdesarrollados (esenciales en el terreno productivo textil) que favorecen a empresas multinacionales a cambio de cualquier tipo de beneficio o arbitrariedad (Ramonet, 2001; Caves, 2002). Olivan (2015) señala que en Marruecos

Las fuerzas sociales han emprendido una gigantesca batalla en este campo. Es de notar que la misma nueva constitución de 2011 se ha posicionado elevando al rango constitucional la lucha contra la corrupción y estableciendo estructuras con ese reconocimiento para desalojar esta lacra. Sin embargo, después de cuatro años de experiencia mi opinión es bastante negativa. Por decirlo en claro. Marruecos ha fracasado en ese empeño de modernidad. [...] se está instalando una nueva modernidad pero que es tan corrupta como la anterior. 


\subsection{Condiciones de los trabajadores}

El abuso de trabajadores en situación de necesidad es algo que debe ser evitado, situación que no se corresponde en muchos casos con la realidad productiva textil (sobre todo en países subdesarrollados). Para Ryder (2015)

Nuestro mundo ha cambiado mucho en el último siglo - y no sólo por la tecnología- En 2050, la población mundial superará los nueve mil millones de habitantes. El número de personas mayores de 60 años o más se habrá triplicado. Tres cuartas partes de los ancianos vivirán en países que ahora conocemos como en desarrollo, y la mayoría de ellos serán mujeres. Estos cambios demográficos revolucionarán aún más los mercados de trabajo, los sistemas de seguridad social, el desarrollo económico y social.

La pérdida de trabajo como daño colateral ha generado importantes flujos migratorios en su búsqueda, en muchos casos por un nuevo desarrollo industrial y en otros a la inversa, por haberlo perdido. Según Ditty (2015)

China manufactura un estimado de 65 por ciento de todos los textiles del mundo. Otros de los principales países y economías emergentes manufactureras de confecciones y textiles son la India, Camboya, Bangladesh y Turquía, donde los agricultores y trabajadores comúnmente ganan menos de un salario digno y muy poca protección social.

Esta situación no escapa de occidente donde en el Reino Unido al menos 700.000 personas trabajan con contratos de cero horas ${ }^{24}$, por tanto, se está instalando un nuevo sistema de esclavismo del siglo Xxi, el precariado (Standing, 2013) . Las ET además de subcontratar su producción, deben contribuir a través de sus valores y su ética (no solo a través de la exigua legislación existente) a una correcta ponderación de la fuerza laboral en la medida de que se benefician del producto final, además de interiorizar que tienen la capacidad de estabilizar o desestabilizar territorios con su sola presencia, a través de sus inversiones o por el contrario, con el cierre de fábricas y cancelaciones de pedidos ante determinados proveedores.

\subsection{Productividad}

La productividad consiste en la relación entre los productos obtenidos y el tiempo invertido para su elaboración, teniendo presente que el incremento de tiempo invertido en la elaboración de un bien no necesariamente va aparejado al aumento de valor del mismo. Es un predictor que indica de una manera cuan-

\footnotetext{
24 «Analysis of Employee Contracts that do not Guarantee a Minimum Number of Hours» informe elaborado por la Oficina Nacional de Estadísticas del Reino Unido el 25/02/2015, disponible en http://www. ons.gov.uk/ons/dcp171776_396885.pdf.
} 
titativa si se están cumpliendo con los objetivos presupuestados para la elaboración de ese bien o servicio.

La competitividad se define por la productividad con la que un país utiliza sus recursos humanos, económicos y naturales (Fernández et al., 2010; Cuatrecasas, 2012; Hitt et al., 2012; y Pozen, 2013). La productividad inexorablemente decidirá el nivel de vida de un país —y de una fábrica一, además de fijar los salarios del sector en curso, los costes del día a día y la capacidad de negociar, ya que a mayor productividad mayor capacidad, gráficamente como la ley de los vasos comunicantes. Para Horel (2015) los "Beneficios a corto plazo no es compatible con la ética».

La productividad en el sector textil (y en otros) es deseable, pero no puede estar por encima de los derechos fundamentales. De ahí que, sin medidas correctoras a través de una mejora normativa, formación, educación, valores empresariales o generación de pertenencia al proyecto o grupo empresarial, no harán más que fundir a los trabajadores usándolos como recambios unos de otros «cual galera romana en guerra» mientras la fotografía de la productividad, pese a cumplir los objetivos marcados, no deja de ocultar la realidad existente detrás de esa misma cámara como son una productividad sin límites y muchos trabajadores sin futuro, sobre todo determinados trabajadores en riesgo ${ }^{25}$.

\subsection{Competencia}

El crecimiento de la competencia mundial no deja lugar al descanso, incluso forzando a los antiguos proveedores internos a competir agresivamente en un mercado abierto por conseguir el próximo pedido, haciendo variar los productos, procesos y mercados, etc., lugar donde los factores tecnológicos cobran gran relevancia (Heuskel y Costa, 1999: 36). El experto científico y visionario Stephen Hawkinfg (2015) en relación a la tecnología afirma

Si las máquinas llegan a producir todo lo que necesitamos, el resultado dependerá de cómo distribuyamos las cosas. Todo el mundo podría disfrutar de una vida de lujo si la riqueza resultado de esa producción se reparte, o la mayoría de la gente podría terminar siendo miserablemente pobre si los dueños de las máquinas tienen éxito al presionar en contra de la redistribución de la riqueza. De momento, la tendencia parece ir hacia la segunda opción, con la tecnología provocando una desigualdad cada vez mayor.

25 El líder contra la explotación infantil que incomoda a las grandes multinacionales señala que « $E l$ $100 \%$ de la producción de Zara en Asia es trabajo infantil», confiesa Ehsan Ullah Khan, líder pakistaní contra la esclavitud de niños y niñas, texto elaborado por A. Justo a través de Eldiario.es del 28/04/2015, disponible en http://www.eldiario.es/canariasahora/sociedad/esclavitud-infantil-trabajo-Asia-ninos_0_382161784.html. 
Los gestores de la producción no tienen ninguna traba gubernamental para maximizar los beneficios y, por tanto, su productividad, "Las reformas estructurales para potenciar el aumento de la productividad son una prioridad general [...] muchas economías de mercados emergentes tienen que centrar su atención en reforzar la productividad de los servicios internos y otros sectores de bienes no transables, que no han avanzado tanto como los sectores de bienes transables ${ }^{26}$, y en mejorar sus regimenes de inversión ${ }^{27}$.

La mejora de la competencia así como su regulación es deseable, pero ¿el mercado es el que la debe de regular? En ese contexto se entiende que una competencia textil sin límites unida a una legislación mínima afecta a las condiciones de los trabajadores. Según (Hernández Zubizarreta \& Ramiro, 2015)

Las ET tienen una responsabilidad solidaria con sus filiales, así como con toda la cadena de proveedores, contratistas y subcontratistas, ya que comparten la responsabilidad por las violaciones de los derechos civiles, políticos sociales, económicos, culturales y medioambientales —al estar conectadas mediante las prácticas económicas - con las compañías multinacionales. Esta responsabilidad solidaria es una cuestión esencial, teniendo en cuenta la práctica habitual de las grandes corporaciones de externalizar costos, riesgos y responsabilidades al tiempo que obtienen grandes beneficios.

Circunstancia ésta que puede pasar de abuso a delito, aunque sin medios para combatirlos ni legislación a la que recurrir.

\subsection{Poder de la industria}

Según Tom Boyd (2014), director para el sur de Europa de Clarks «La gran distribución ha introducido en la mente del consumidor que los zapatos son moda» evidenciando el poder e influencia de la industria, tanto a través de sus productos, como a través de sus relaciones comerciales. Paralelamente muchas empresas han optado - debido a una aclamación popular - por establecer mecanismos que faciliten o abran el camino hacia un trabajo más digno para muchos de sus trabajadores (fábricas textiles en países con vías de desarrollo), proveedores, grupos de interés, así como un trato más ético hacia los consumidores (Server \& Villalonga, 2005) o usuarios que hacen uso de sus productos. Aunque se generen artificialmente por parte de determinadas empresas sentimientos y actitudes positivas hacia sus marcas (Aaker, 1991; Low y Lamb, 2000; Dean, 2004) o

26 Bien transable es todo aquel que se puede exportar e importar, se refiere principalmente a cosas, en general no se aplica los servicios.

27 Perspectivas de la Economía Mundial: Introducción, resumen ejecutivo y capitulos 1 y 2; Octubre de 2013, Fondo Monetario Internacional pags. 19 y 24, disponible en http://www.imf.org/external/spanish/pubs/ft/weo/2013/02/pdf/texts.pdf. 
pretendan, según Yoo et al. (2000) y Chen (2001), generar una predisposición ${ }^{28}$ mayor hacia el uso de ese producto (marca) o servicio a través de la generación de ese deseo, actualmente está emergiendo un empuje social que hace detestar toda clase de abusos en la cadena de valor o contra el medio ambiente, que recordemos, es de todos y no propiedad de ninguna empresa aunque paguen la "contribución» del lugar donde se asientan. Este poder e influencia de la industria mal utilizada genera disfunciones y falta de confianza.

No olvidemos que el reconocimiento global unido a la disponibilidad y servicio mostrado, aumenta la clientela mediante su reforzamiento positivo. Esto forma parte de las más elementales formas del marketing globalizado, «una marca fuerte supone para la empresa una plataforma para el lanzamiento de nuevos productos y para la obtención de licencias" (García, 1997: 103-107). Aunque también «Las personas reconocen que las empresas globales tienen una extraordinaria influencia, tanto positiva como negativa, sobre el bienestar de la sociedad. Esperan que las compañias aborden los problemas sociales relacionados con lo que venden y con la forma en que hacen negocios" (Holt et al., 2004).

Para Álvarez del Blanco (1997: 44), las marcas $^{29}$ que perdurarán en el tiempo serán aquellas cuya filosofía no sea únicamente la de vender, sino la de captar, satisfacer y retener a los clientes.

\subsection{Legislación}

Existe mucha argumentación al respecto, como la de Chakravarthi (2004: 27-36), detallando la asimétrica división internacional, epicentro este de muchos de los conflictos y de las desigualdades existentes en el marco textil internacional. Con la legislación globalizada no olvidemos que se cede soberanía (Bodemer, 1998: 54-69), o se establece una «soberanía compartida» como indica Rodríguez (1999). Teniendo en cuenta que más de la mitad de las principales economías del mundo ya no son propiedad de sus respectivos países, sino de sus

28 "Desvelamos los seis trucos secretos de las tiendas para hacerte comprar más" noticia elaborada por Berta Mina a través de Elconfidencial.com del 7/09/2015 en la que se señala "Ya sabes que las cadenas de ropa usan estrategias de marketing para que compres a lo loco y te quedes mucho más tiempo en sus tiendas".

— «El capitalismo necesita que la gente consuma más e incentiva un conjunto de necesidades muchas de ellas ficticias [...]» Información extraida a través de una entrevista realizada a José Múgica — ex presidente de Uruguay - realizada por Christophe Ventura a través de la publicación Le Monde Diplomatique del 09/2015 en pag. 9.

29 La identidad de la marca y la marca, son conceptos diferentes, siendo la identidad la manera en la cual una compañía desea que su marca (a través de sus productos y servicios) sea percibida mientras que la imagen de marca como tal, muestra como es percibida esa marca por los consumidores y usuarios así como las señales que se emiten a través de la misma. A través del documento de investigación "Las ventajas de disponer de una marca fuerte en los mercados actuales", texto elaborado por M . J José García Rodríguez en la publicación Investigaciones Europeas de Dirección y economía de la Empresa V.3, N.o 3 de 1997, pags 93-107. 
inversores, el capital privado puede generar problemas de equidad (Friedman, 1966).

Actualmente, el marco regulatorio de las empresas transnacionales es reducido, o amplio, en relación de quién lo examine y bajo qué perspectiva. Además, se orienta hacia el Derecho Comercial Global, usando, incluso, apéndices legales para su control o para su expansión. Muchas veces su regulación es adhoc, realizándose a conciencia para dejar una parte concreta en un limbo legal y, precisamente, realizar actividad en ese espacio (Sánchez 2004: 256-258). El estado legisla no legislando, como el derecho internacional de los derechos humanos $^{30}$, derecho societario, laboral y comercial, principios UNIDROIT ${ }^{31}$, INCOTERMS, organismos internacionales (Fondo Monetario Internacional, Banco Mundial, OCDE, acuerdos de Bretton Woods, etc.) o todo tipo de RSC empresarial, no siendo esta, una fuente de derecho como tal, aunque propiamente la forma directa de control es realizada a través de la participación en su capital, pudiendo ser condicionada su conducta a través de un control ${ }^{32}$ indirecto ejercido por empresas nacionales $\mathrm{u}$ otros organismos.

Cabe preguntarse, por tanto, qué capacidad de maniobra tiene un estado o normativa internacional ante cualquier incumplimiento laboral o necesidad urgente que precise mover un entramado de este calibre. Las empresas transnacionales se caracterizan por no realizar una buena digestión de las obligaciones jurídicas impuestas por terceros (porque a que a nadie le suele gustar que le digan lo que tiene que hacer), sobre todo las de determinados países o tribunales que emanan de los mismos (Giner, 2011; Zamora, 2012). De hecho, se está redactando un texto entre Estados Unidos y la UE para desarrollar una Asociación Transatlántica para el Comercio y la Inversión (TTIP) —cuya negociación ha sido calificada como «clandestina» por el premio nobel de economía Joseph Stiglitz (Eldiario, 2014)—, que tenga capacidad de sortear dichos tribunales para someterse solo a determinadas organizaciones internacionales de arbitraje, reconocidas por ellas según una amalgama de normativas y re-

30 Existe gran cantidad de normativa no vinculante jurídicamente hablando pero recomendable seguimiento y aplicación como es el caso de "Las Directrices de la Organización para la Cooperación y el Desarrollo Económico (OCDE) para las empresas multinacional de 1976", "La Declaración tripartita de principios sobre las empresas multinacionales y la politica social de la Organización Internacional del Trabajo (OIT), de 1977», "El Pacto Mundial de las Naciones Unidas (UN Global Compact) del 2000», "Los Estándares de desempeño de sostenibilidad social y ambiental de la Corporación Financiera Internacional (IFC), del 2006", "La Guía de Responsabilidad Social, ISO 26000, de la Organización Internacional de Estandarización (ISO), del 2010", etc.

31 «UNIDROIT» (Instituto para la Unificación del Derecho Privado) se inspira en modelos de tratados internacionales de temas mercantiles como la Convención de las Naciones Unidas sobre los Contratos de Compraventa Internacional de Mercaderías de 1980 o Convención de Viena de 1980.

32 Existen diferentes iniciativas de control y recomendación no vinculante como el «Tratado Internacional de los Pueblos para el Control de las Empresas transnacionales", disponible en http://omal. info/IMG/pdf/tratado_de_los_pueblos___castellano.pdf 
comendaciones, vinculante y dejando a determinados países (los más pobres) sin instrumentos legales de supervisión o protección. Preguntado el profesor Teitelbaum (2015), experto en ET, sobre la posibilidad de establecer o articular algún mecanismo con capacidad de controlar/regular a las ET señala que

Sería necesario, pero es irrealizable en la actual relación de fuerzas dentro del sistema dominante. Prueba de ello es que desde hace 40 años están fracasando las sucesivas iniciativas para establecer un marco jurídico vinculante para la empresas transnacionales y que en cuando se estableció el Estatuto para la Corte Penal Internacional no prosperó la propuesta francesa (apoyada por una sola ONG entre el millar presente en Roma) de incluir a las personas jurídicas (es decir entre ellas las grandes empresas) entre los sujetos imputables de los delitos contemplados en el Estatuto. Y que entre esos delitos, no figuran los delitos económicos, sociales y culturales.

\subsection{Arbitraje}

El CIADI es el organismo especializado en la resolución de conflictos más conocido y usado entre inversionistas y estados a nivel internacional. Solo ha habido hasta la fecha dos casos de litigio de un Estado hacia un inversionista. La práctica totalidad es a la inversa: actualmente hay unos 100 casos en trámite, con unas cantidades en disputa de en torno a 25.000 millones de dólares, que inevitablemente saldrán del bolsillo de los contribuyentes. Ese organismo ha creado para su funcionamiento comisiones de conciliación y tribunales de arbitraje ad-hoc. Está ratificado por 144 países y entre sus características destaca que cualquier inversionista puede acceder a él de manera directa (Teitelbaum, 2010). Incluso existen mecanismos complementarios para países que, aun no habiendo suscrito el convenio de Washington (como México y Canadá), tengan acceso al organismo y, por tanto a instar un procedimiento. Las resoluciones de CIADI son vinculantes, inapelables e irrevisables ${ }^{33}$, objeto actual de gran controversia: por un lado, al haberse demostrado que en algunos casos los miembros del tribunal tienen intereses con alguna de las partes y, por otro lado, al no tener en cuenta las Constituciones de determinados países, incluyendo su derecho propio o normativa de derechos humanos, volviéndose en obligatorias para los estados firmantes ${ }^{34}$. Atrás quedaron viejas añoranzas de utilizar el arbitraje como último recurso, dando paso a la articulación de herramientas jurídicas como me-

33 Las resoluciones del arbitraje (laudos) permiten decisiones suplementarias y/o revisiones, además de recursos anulación (en este caso se establecerá un comité ad-hoc), aclaración o revisión. $\mathrm{Al}$ inicio del procedimiento cabe la posibilidad de que el estado demandado interponga objeciones a la jurisdicción o competencia del tribunal, dando paso a lo que se denomina, fase de competencia, culminándose igualmente en una decisión (en lugar de laudo) en la que no cabe recurso,.

34 En algunos casos se invoca "pacta sunt servanda" del artículo 26 y 27 de la Convención de Viena sobre el Derecho de los Tratados según el mismo «una parte no podrá invocar las disposiciones de su derecho interno como justificación del incumplimiento de un tratado", disponible en http://www. derechos.org/nizkor/ley/viena.html. 
dio de ataque y contención, siendo un nuevo mecanismo de guerra entre empresas y estados. Según Van Harten (2010: 5)

El arbitraje de tratados de inversión es una importante pieza jurídica e institucional del rompecabezas neoliberal porque impone unas restricciones legales y económicas excepcionalmente poderosas sobre los Gobiernos y, por extensión, sobre las opciones democráticas, con el fin de proteger de toda regulación los bienes de compañías multinacionales.

Muchas de las quejas, principalmente de los estados - y ciudadanos-, consisten en echar en falta mecanismos de admisibilidad y apelación, junto con sistemas de plazos preceptivos, porque se eternizan los procedimientos objeto de litigio y se generan, en muchos casos, facturas propias del presupuesto anual en sanidad de muchos países. Constituye una fuente de negocio multimillonario para determinados organismos dependientes de CIADI, bufetes internacionales de abogados etc, etc., a la vez que situaciones paradójicas ${ }^{35} \mathrm{o}$, cuanto menos, sorprendentes, ya que en muchos casos la honorable profesión de intérprete de las normas como es ser abogado, pasa a ser de desarrollador de un articulado legal ad-hoc, lo que genera una asimetría de facto entre los países o ciudadanos que quieren defender a sus inversiones o trabajadores frente a grandes imperios económicos que no dependen de los tribunales donde desarrollan su actividad.

\subsection{Lobbies}

Un lobby es un colectivo de presión compuesto por diferentes miembros (pudiendo ser de diferentes orígenes, culturas, lenguas, empresas, sectores, etc.)

35 "Cuando la injusticia es negocio: Cómo las firmas de abogados, árbitros y financiadores alimentan el auge del arbitraje de inversiones", texto elaborado por Pia Eberhardt y Cecilia Olivet a través de Corporate Europe Observatory y Transnational Institute en Bruselas / Amsterdam, noviembre de 2012, pag. 7 y sgtes donde se explica parte del procedimiento arbitral internacional de inversiones con situaciones como: Tres multinacionales de abogados (Freshfields UK, White y Case y King y Spalding, EE.UU.) han participado en 130 casos de tratados de inversión en 2011; 15 árbitros, casi todos ellos procedentes de Europa, los Estados Unidos o Canadá, han resuelto el 55\% de todas las disputas conocidas en base a tratados de inversión o que varios de los árbitros de renombre que participan en las resoluciones han sido miembros de juntas en grandes multinacionales (siendo parte de procesos en las demandas).

- Según Harm Schepel profesor y experto en ET «No son tantos [los árbitros]. Es verdad que hay centenares de personas que han trabajado para un tribunal de arbitraje, pero la Corte de Arbitraje la forman medio centenar de expertos aproximadamente. ¿Quiénes son? Bueno, yo diría que una mayoría posee gran experiencia en arbitrajes comerciales, habiendo pasado muchos de ellos por la Cámara Internacional de Comercio, que está en París. Estos expertos están bregados en el arbitrio de las diferencias contractuales entre empresas privadas, que no estados. Por ejemplo, si hay un litigio entre una firma española y una china la empresa española no acudirá a la Justicia china porque no entenderá nada. Probablemente tampoco busque Justicia en España a un problema ocurrido en China, porque llevará mucho tiempo y dinero. Así que lo mejor es elegir un actor neutral, un árbitro que agilice las cosas.», noticia elaborada por Pau Collantes a través de Eldiario.es del 21/03/2015. 
con una misma finalidad, que no es otra que la de conseguir un objetivo preestablecido que favorezca sus intereses (o para lo que han sido contratados, ya que en muchos casos mueve tal cantidad de recursos que son propios de la multinacional o permanentes del sector), pasando para ello por una negociación/presión/contacto para cambiar cualquier tipo de legislación, normativa, proyecto etc., en beneficio propio. Para ello, cuentan con sus propias herramientas (o ajenas si fuera necesario) como think tanks o los bufetes de abogados, fundaciones, asociaciones, ex políticos ${ }^{36}$, etc.

Normalmente tienen contacto con órganos legislativos (aunque también con ejecutivos y judiciales), ya que son los que finalmente elaborarán cualquier tipo de legislación vinculante que pueda favorecer o perjudicar los intereses que ellos representan. Por ejemplo, existen grupos de presión farmacéuticos que influencian para aumentar el tiempo de permanencia de las patentes de los medicamentos en manos de las multinacionales; normalmente son diez ańos, pero a las empresas farmacéuticas no les interesa que de manera libre se acceda a su patente (en muchos casos de manera entendible después de una gran inversión) o que se pueda fabricar un medicamento genérico 100 veces más económico que el que distribuyen algunas de las multinacionales. En la industria química relacionada con el textil, es vital la actualización de los listados de sustancias peligrosas (ej. afectación de los disruptores endocrinos) para mejorar la seguridad de los consumidores, circunstancia que, aun siendo actualmente "legal», está sometida a grandes presiones para ralentizar su actualización o valoración de estudios independientes. Por tanto, presionan a ministros, médicos, químicos, eurodiputados, miembros de diferentes senados, como el de EE.UU. o UE, y en definitiva a cualquier órgano regulatorio para que la legislación o normativa que se desarrolle no menoscabe sus intereses (Ramonet, 2009; Gotzsche, 2014), haciendo que perjudique a la competencia o presionando para que las nuevas legislaciones no contengan salarios mínimos para los trabajadores, condiciones de trabajo mejores, etc., de manera obligatoria y vinculante.

El borrador de la nueva ley pretende regular estándares mínimos, como: contratos laborales, indemnizaciones por despido, negociación colectiva, reducción del tiempo de trabajo y aumento de salarios. Las empresas están amenazando al gobierno chino con abandonar las inversiones en el país (Global Labor Strategies, 2006: 1-12)» a través de (Hernández Zubizarreta, 2009: 137).

En un principio los lobbies son legales, pero evidentemente detrás de muchos de ellos se desarrollan prácticas más propias de servicios de inteligencia

\footnotetext{
36 Ejemplo de lobby «ICP está especializada la promoción de sinergias entre instituciones gubernamentales y el sector público-privado (PPP)", utilizando "Agendas de alto nivel y relaciones públicas» y por último "ICP mantiene importantes lazos económicos y politicos [...]» consultado el 01/12/2015 a través de la propia web http:// www.icpconsulting.es/es/.
} 
(contravigilancia incluida) que de asesores-consultores que obran de buena fe (Lobeto, 2014). En la UE los lobbies están regulados a través del registro de transparencia ${ }^{37}$, pero el problema viene cuando se regula algo a medida para que el resto de actividades quede ad-hoc sin regular y «jugar el partido» en ese espacio.

\subsection{Cambio climático}

Pachauri (Elpaís, 2014) señala que "Muchas de las personas más vulnerables al cambio climático apenas han contribuido y contribuyen a las emisiones de gases de efecto invernadero", explicaba en la presentación el presidente del IPCC [Grupo Intergubernamental de Expertos sobre el Cambio Climático] "No será posible afrontar el cambio climático si los distintos agentes anteponen sus propios intereses de forma independiente; solo se alcanzarán resultados positivos con respuestas colectivas, en particular de la cooperación internacional".

Lo que significa que países que no contribuyen, sufren sus consecuencias igualmente y con menos recursos para paliar sus efectos. Según el Banco Mundial $^{38}$

A medida que las ciudades costeras de África y Asia se expanden, muchos de sus habitantes más pobres están siendo empujados hacia los bordes de las tierras habitables y las zonas en mayor peligro de ser afectadas por el cambio climático. Sus asentamientos informales se aferran a las orillas de los ríos y se agrupan en áreas bajas con deficiente drenaje, escasos servicios públicos, y sin protección contra tormentas repentinas, aumento del nivel del mar e inundaciones.

Lo que, además de ser un drama, lo convierte en una situación que agrava la necesidad existente de alimentar a sus familias, contribuyendo esta situación a la aceptación de trabajos que en condiciones normales no se aceptarían. En términos económicos, según el «Informe Stern», los costes globales y los riesgos como consecuencia del cambio climático equivaldrán al menos a la pérdida de un $5 \%$ del PIB global anual, ahora y para siempre (los daños podrían alcanzar un $20 \%$ o más del PIB) para lo que se propone al menos una inversión de un $1 \%$ del PIB. Como señala (Morin, 2015: 2)

Debido a que la humanidad se encuentra en la actualidad amenazada por peligros mortales (multiplicación de las armas nucleares, desencadenamiento de fanatismos y multiplicación de las guerras civiles internacionalizadas, degradación acelerada

37 "Registro de transparencia de la UE» en el cual se puede buscar, registrar o actualizar una "organización», disponible en http://ec.europa.eu/transparencyregister/public/homePage.do

38 «Qué significa el cambio climático para África, Asia y los pobres que viven en las zonas costeras?» información elaborada por el Banco Mundial el 19/06/2013 disponible en http://www.bancomundial.org/es/ news/feature/2013/06/19/what-climate-change-means-africa-asia-coastal-poor. 
de la biosfera, crisis y desajustes de una economía dominada por una especulación financiera desenfrenada), la vida de la especie humana y, de forma inseparable de la biosfera pasan a ser un valor primario, un imperativo prioritario.

Hoy en día, por un lado el hecho de pasar por alto esta catarata de estudios internacionales y los resultados concluyentes por parte de investigadores que señalan grandes cambios en aspectos migratorios ${ }^{39}$, climatológicos, sociales, industriales o económicos parapetados en determinados desarrollos industriales anquilosados en el pasado (maquinaria antigua y contaminante al igual que legislación obsoleta), así como negar el continuo cambio climático, que a día de hoy ya entra a través de nuestras ventanas y pulmones, aún podría agravar más la situación de muchos sectores y truncar la economía de muchos países, principalmente el de los territorios más desfavorecidos ocultando situaciones como las descritas por Muñoz (2007): «el 60\% de los ríos están contaminados y el 15\% secos; se han perdido más de siete millones de hectáreas de cultivo en los últimos treinta años, el 60\% de las aguas residuales no se depuran, 300 millones de personas no tienen aún acceso directo a la red de agua potable, el 20\% de la población vive en áreas contaminadas», según un reciente estudio de (Kelley et al., 2015: 1)

Hay evidencia de que la sequía 2007-2010 contribuyó al conflicto en Siria. Fue la peor sequía en el registro instrumental, causando la pérdida de cosechas generalizada y una migración masiva de familias campesinas a los centros urbanos. [...] Llegamos a la conclusión de que la influencia humana en el sistema climático está implicada en el actual conflicto sirio.

\subsection{Derechos humanos}

A pesar de que muchas industrias van mejorando sus índices de corrupción e interiorizando el respeto a los Derechos Humanos como señala John Gerard Ruggie $^{40}$, Rulli y Justo (2012: 38-39) señalan que «Los Estados no renuncian a sus obligaciones internacionales de derechos humanos por privatizar la prestación de servicios con un posible impacto sobre el disfrute de los derechos humanos. [...] Las consecuencias pueden ser perjudiciales para la reputación del propio Estado y (a)traerle problemas legales».

39 Cruz Roja destacó, en su Informe Mundial sobre Desastres 2001 que hubo más personas obligadas a abandonar sus hogares a causa de los desastres ambientales que debido a la guerra. Información extraida a través del Informe World Disasters Report a través de International Federation of Red Cross and Red Crescent Societies, 2001. World Disasters Report. Focus on Recovery. International Federation of Red Cross and Red Crescent Societies, Geneva. Otro informe del año 2010 también elaborado por la Cruz Roja está enfocado a los riesgos urbanos y recoge consecuencias climáticas como inundaciones, migraciones forzadas, etc., disponible en http://www.ifrc.org/Global/Publications/disasters/WDR/WDR2010-full.pdf.

40 John Gerard Ruggie, de 2005 a 2011 trabajó como Representante Especial del Secretario General de las Naciones Unidas para los Derechos Humanos y Empresa, elaborando Los Principios Rectores de la ONU sobre Empresas y Derechos Humanos, poniendo especial hincapié en países con conflicto. 
A través de la instalación en determinados países con fragilidad política, jurídica o simplemente estados fallidos como puede ser Somalia, o salidos de una guerra $^{41}$ como Camboya o Vietnam, se puede generar un efecto adverso al esperado, desarrollando estructuras societarias más propias de la antigüedad que de una empresa respetada, sensible y responsable tanto con los trabajadores así como con el entorno, sin olvidar además de lo expuesto anteriormente que según el Derecho Internacional Humanitario, una empresa puede ser responsable penalmente de la acción (omisión de ayuda). Según un informe ${ }^{42}$ del año 2015 de Intermon Oxfam titulado Derechos que penden de un hilo

Mientras asistimos impasibles a la consolidación de este sistema de producción [...] de prendas de vestir para exportación, es desde hace décadas, sinónimo de violación de derechos humanos y laborales para una cantidad significativa de trabajadoras y trabajadores en los países en desarrollo: salarios de 1,3 euros diarios, jornadas de 68 horas semanales, ambiente insalubre, ausencia de prestación en caso de enfermedad, restricciones a la afiliación sindical, etc., es lo que caracteriza la jornada laboral de las mujeres en algunas megafactorías textiles en la India asociadas a grandes marcas internacionales (incluidas marcas españolas).

A modo de síntesis en el siguiente gráfico N. ${ }^{1} 1$ se destacan los factores que pueden explicar la falta de comportamientos éticos en las prácticas de producción y logística de las empresas multinacionales.

\section{Gráfico 1}

Factores que pueden explicar la falta de comportamientos éticos en las prácticas de producción y logística de las empresas multinacionales

\begin{tabular}{lll}
\hline \multicolumn{1}{c}{ Factores } & \multicolumn{1}{c}{ Incidencia positiva } & \multicolumn{1}{c}{ Incidencia negativa } \\
\hline $\begin{array}{l}\text { 1. Globalización } \\
\text { 1. Aumenta posibilidades de crecimiento }\end{array}$ & $\begin{array}{l}\text { 1. Redistribución y afectación desigual de los pro- } \\
\text { cesos. Mundialización sistémica. }\end{array}$ \\
\hline $\begin{array}{l}\text { 2. Libre circulación de } \\
\text { capitales }\end{array}$ & 2. Existencia de controles económicos ante abusos & $\begin{array}{l}\text { 2. Facilidad de ocultación societaria o creación } \\
\text { ad-hoc. }\end{array}$ \\
\hline
\end{tabular}

41 Además de otros conflictos internacionales como los de Corea, Kurdo en Irán, Cachemira, Baluchistán, Palestino-Israelí, Birmania (mirado de reojo por la industria textil ante sus grandes posibilidades comerciales), Papúa, norte de India y Cachemira, Colombia, Filipinas, Perú, Casamance (entre Senegal y Gambia), Xinjiang (China), Cabinda (Angola), Rusia (Chechenia), Ogaden (Etiopía), Turquía Independencia del Kurdistán), Magreb, Yemen, Delta del Níger (Nigeria), Tailandia, Sudan del norte y Sudan del Sur, Yemen, Bahréin, Egipto (Sinaí), Líbano, Argelia, Chad, Libia, República Centroafricana, Ucrania, Somalia, Sri Lanka o Uganda entre muchos otros que crean inestabilidad a la vez que "determinadas» oportunidades comerciales.

42 "Derechos que penden de un hilo", informe elaborado por Intermon Oxfam el 04/2015, disponible en https://oxfamintermon.s3.amazonaws.com/sites/default/files/documentos/files/DerechoQuePendenDeUnHilo.pdf. 


\begin{tabular}{ll}
\hline \multicolumn{1}{c}{ Factores } & \multicolumn{1}{c}{ Incidencia positiva } \\
\hline $\begin{array}{l}\text { 3. Empresas } \\
\text { transnacionales }\end{array}$ & $\begin{array}{l}\text { 3. Registro, promoción y regulación de ET así como de sus } \\
\text { filiales }\end{array}$ \\
\hline $\begin{array}{l}\text { 4. Corrupción. } \\
\text { 4. Mayor control ante órganos externos así como sanciones a } \\
\text { la hora de producir o vender. }\end{array}$ \\
\hline $\begin{array}{l}\text { 5. Condiciones para los } \\
\text { trabajadores }\end{array}$ & $\begin{array}{l}\text { 5e legislación exigua existente. Ratificación de un mínimo de } \\
\text { tratados de OIT para poder producir en determinados países. }\end{array}$ \\
\hline
\end{tabular}

6. Productividad

6. Objetivos productivos realizables, revisables y sancionables por organismos ajenos a la industria textil en caso de abuso.

3. Capacidad de deslegitimación para los Estados ante falta de recursos y limitación en la capacidad de movimientos de los mismos.

4. Competir en mismo mercado con diferentes reglas originando desigualdad y falta de ética.

5. Graves perjuicios sociales y personales (físicos y psíquicos) para los trabajadores como exclusión, abusos, alienación, etc., así como para los países, generalmente pobres.

6. Desde desafección al trabajo, a la empresa, a guerras de todo tipo al enfrentar empresas (y sindicatos), pueblos o países por una oferta mejor que la de su competencia.

7. Competencia

7. Competencia regulada donde se eliminen prácticas execrables que afecten a derechos fundamentales o abusos inclusive de grandes empresas a pequeñas. Existencia de organismo internacional donde acudir que no dependa del país que permite abusos.
7. Si se genera a partir de abusos o va más allá de limitaciones físicas, legislación o recomendación aplicable se convierte en una falta de DD.HH, por tanto en delito a perseguir.

8. Capacidad de creación de una suprademocracia sin ningún tipo de sufragio solo accesible para unas élites.

9. Destrucción de parte del tejido empresarial local ante la aparición de ET además de generar competencia desleal pero «legalizada» a través de tratados de libre comercio, bilaterales, de inversión, etc.

10. Deslegitimación de Estados y órganos legislativos competentes por otros en los que prima el factor económico así como su legislación mercantil. ces, inspección de trabaj, sindicatos intento o, sindicatos internacionales) y no través de instrumentos de resolución de conflictos donde se pueda ser juez y parte.
11. Regulación efectiva de lobbies y puertas giratorias, con periodos de inactividad para funcionarios / políticos que deseen trabajar en los mismos. Legalizar asimetrías normativas no legitima ejercicios de actuaciones que no lo son.
11. Destrucción del sistema de igualdad y competencia leal, generando abusos como «las puertas giratorias» o el intercambio de roles políticolobbista-político sin regulación efectiva ni medios comprometiendo cualquier sistema democrático.

12. Generación de nuevos paradigmas migratorios a la vez que aparición de continuas situaciones de necesidad y guerras para millones de personas, siendo mano de obra dispuesta a prácticamente todo.

13. Elaboración de productos en condiciones deshumanas pese a los imparables programas de RSE o publicidad, generando asimetrías normativas difícilmente salvables (aunque fácilmente identificables).

Fuente: elaboración propia. 


\section{Conclusiones}

Las relaciones dentro del sector textil internacional son complejas a la vez que funcionales, donde la frenética actividad internacional compuesta por miles de proveedores, millones de usuarios y de prendas fabricadas junto a sociedades mercantiles ad-hoc, funcionan como una gran sinfonía pero no para todos igual.

Son muchos los actores y fuerzas que gravitan de manera indirecta en el proceso industrial textil, teniendo a su vez una gran incidencia e influencia sobre todo lo que les rodea. Los imparables procesos de globalización, han conseguido afectar a trabajadores, sindicatos y sociedades de países avanzados hasta el punto de no poder competir con otros países generalmente más desfavorecidos, no solo debido a la oferta de menores costes laborales, sino por las condiciones de los mismos, en muchos casos ínfimas, carentes de control alguno, así como por la ausencia de sindicatos, formación y representatividad de los mismos, todo ello amparado con una legislación - y gobiernos nacionales- que favorecen a las empresas que desean desarrollar su actividad laboral allí.

El mercado textil internacional vive en una puja laboral y social continua, en donde ya no se juega con el próximo pedido, sino con la existencia de muchas empresas y sectores como se conocían antaño, véase la industria textil de EE.UU. o de la UE que no han sabido ni podido competir contra la mano de obra y condiciones legales creadas a medida (convenios, zonas de libre comercio, baja presión fiscal/laboral) en Bangladesh, India, Vietnam o inclusive Marruecos por citar algunos ejemplos.

El conglomerado textil internacional es un sistema bien armado, una pieza de fina orfebrería jurídica en el que se dispone de legislación a medida - $\mathrm{O}$ ausencia deliberada de la misma- que permite la producción textil sin límites en lugares donde en muchos casos no existe legislación sobre el medio ambiente, los sistemas sociales son muy precarios y hablar de derechos humanos no deja de ser una quimera pese a existir gran cantidad de recomendaciones ${ }^{43}$, eso sí, no vinculantes y sin medios efectivos. En este contexto es en el que se mueven las empresas transnacionales textiles, pudiendo utilizar allí productos potencialmente peligrosos como muchos de los tintes (que están prohibidos en Europa o

43 Según "La empresa del nuevo milenio. De los valores a la acción» (ODM 7 economía y desarro1lo) recomienda diferentes líneas de acción en relación al negocio central y cadena de valor como 1) Traslado de las políticas, sistemas, procedimientos ambientales y sociales de la casa matriz a las filiales, 2) Estandarización de buenas prácticas (como ética, medidas anticorrupción, preservación del medio ambiente, evitar el doble estándar entre casa matriz y filiales o adhesión a certificaciones), 3) Desarrollo local (generando empleo, invirtiendo en capacitación, utilizar redes de proveedores locales, invertir en las plantas de producción, etc.), 4) Productos y servicios accesibles, 5) Desarrollo sostenible, 6) Cambio climático, eficiencia energética y uso de los recursos, 7) contaminación y gestión de residuos, 8) Mercados verdes y 9) Biodiversidad. Disponible en http://ecodes.org/ documentos/RS/ODM7_def.pdf 
deberían estar en suspenso debido a evidencias) a la vez que articulan menores medidas preventivas para los trabajadores (por mucho código de conducta que exista por parte de las empresas involucradas). Paralelamente a nivel global se utilizan listados de sustancias peligrosas o estudios de impacto como si fueran directrices divinas, lo que no forma parte de los mismos, no existe, por tanto se puede seguir utilizando.

Para trabajar con este tipo de asimetrías normativas es necesaria la convivencia de muchos otros actores como son los lobbies que actualmente carecen de regulación efectiva — más allá de recomendaciones voluntarias-. Los sistemas de resolución de conflictos impuestos por las ET a la hora de firmar tratados bilaterales, de libre comercio o de inversión como son los tribunales de arbitraje privado son fundamentales para producir, no es necesario ser juez para aparentemente ejercer como tal y dictar laudos vinculantes en caso de controversia, esquivando a los tribunales nacionales de cada país aunque paralelamente estén obligados a pagar las costas así como sus resoluciones ya que estas si lo son (así lo firmaron en el tratado de libre comercio previo a la inversión). Existe la posibilidad de poder ser parte (abogado) en un proceso y posteriormente en otro ser «juez», circunstancia que deslegitima cualquier tipo de soberanía y justicia más elemental armándose una contrafigura legal, a la vez que determinados países pobres tienen que recurrir a bufetes de abobados muy técnicos y especializados de los que no abundan en el mundo y no existen en países pobres, pero que paralelamente si gestionan gran parte de esos conflictos. Estas situaciones son ayudadas por el actual sistema económico internacionalmente admitido, promoviendo la libre circulación de capitales — pero no de personas-, permitiendo que las ET textiles radiquen la sede social de sus sociedades en aquel paraíso donde menos presión fiscal se ejerza ${ }^{44}$ y por tanto maximizando sus beneficios, basta con ir al notario, crear la sociedad y poner un buzón para que desde allí se puedan gestionar todas las ventas del canal online de una multinacional textil. Estas circunstancias son difíciles de conocer ya que ni siquiera los sindicatos de las empresas matrices textiles tienen acceso a esa información —ni a otras como la gestión de sus filiales o esta es exigua-, realmente las empresas se ocupan de cumplir la ley, todo lo demás es accesorio, independientemente de la creación o destrucción de mercados que dejan a su paso las búsquedas de unos costes menores.

44 "La filial de venta online de Inditex tiene en Irlanda facturó el año pasado 225 millones. Esta empresa, llamada ITX Fashion Limited, es sobre la que el imperio textil español levantó su comercio electrónico en 2007. Desde alli gestionaba las ventas de todos los mercados en los que estrenaba tiendas online, incluidas las españolas. Inditex fue trasladando a España la facturación de todas sus tiendas virtuales europeas. La filial irlandesa, sin embargo, sigue activa y desde alli se gestiona la venta online de tres grandes mercados extracomunitarios, que ascendió a 225 millones el pasado ejercicio.» Noticia elaborada por C. Delgado a través de Elpaís.com del 21/11/2015 disponible en http://economia.elpais.com/economia/2015/11/20/actualidad/1448047144_142134.html. 
Paralelamente, al igual que se desarrollan prendas prácticamente a medida, con un menor tiempo de entrega y con precios en muchos casos mínimos, detrás de esa "cara amable», existe un trasfondo de competitividad y generación de valor en donde cualquier disfunción además de ser un coste accesorio, se introduce dentro del cajón desastre de la RSC. Cabe preguntarse si ese es el lugar apropiado, ya que igualmente se utiliza cuando no existe legislación vinculante y en consonancia con la de países avanzados, ¿tiene más valor la vida de un trabajador de Zelzate que uno de Dhaka?, a la vista está que sí mientras se obtenga un beneficio de esa disfunción creada con precisión de neurocirujano y al amparo de todo un sistema a favor.

Para concluir este trabajo, cabe señalar la diferenciación de conceptos como ser una empresa - o gobierno- socialmente responsable, ético, que cumple la legislación mínima exigible, que genera beneficios, etc., y la capacidad de poder cumplir todos ellos — en mayor o menor medida - y ser a su vez una empresa o sector ajeno a la realidad, además de promover de manera indirecta prácticas inhumanas a través del amparo de los factores que hemos señalado a lo largo de este trabajo. Los recursos con los que cuentan las ET textiles, las convierte en promotoras directas de prácticas inhumanas legalizadas, situación que continuará sine die mientras no exista voluntad de cambio por parte de las organizaciones y gobiernos internacionales, siendo según ellos en estos momentos de fluctuación financiera nada recomendable acometer cambios dentro de un sector poco conflictivo, elaborando bienes de primera necesidad y con alta generación de intereses de todo tipo.

\section{Bibliografía}

Aaker, D. (1991). Gestión del Valor de la Marca: Capitalizar el Valor de la Marca. Madrid: Diaz de Santos.

Aas, K. (2013). Globalization and crime. SAGE Publications Limited.

Álvarez del Blanco, R. (1997). «Enfoque estratégico para el futuro de la marca». Aula abierta, N.o $10,1 .^{\text {er }}$ trimestre.

AnaYa, J. (5 de 12 de 2012). iwgia.org. Foro sobre empresas y DDHH en Ginebra. Disponible online en http://www.iwgia.org/noticias/buscar-noticias?news_id $=724$.

Anguita Olmedo, C. (2010). "La delincuencia organizada: un asunto interior de la unión europea. Concepto, características e instrumentos para su neutralización». Revista española de relaciones internacionales, (2), 152-172.

Atondo, R. (2009). «Reputación corporativa, RSC, sostenibilidad, acción social: ¿De qué hablamos?» Telos: Cuadernos de comunicación e innovación, (79), 66-74.

Bannenberg, B. y Chaupensteiner, W. (2004). Korruption in Deutschland. Hamburgo: Beck.

Barnett, C., Clarke, N., Cloke , P. y Malpass, A. (2005). «The political ethics of consumerism». Consumer, Policy Review, N. ${ }^{\circ}$ 15, 45-51. 
Barroso, F. (2008a). «Ganancia máxima o ganancia óptima». Desarrollo Empresarial. Año XI, N. ${ }^{\circ} 110$.

BARROso, F. (2008b). La responsabilidad social empresarial: un estudio en cuarenta empresas de la ciudad de Mérida, Yucatán. Contaduría y administración, (226).

Becк, U. (1998). ¿Qué es la globalización? Falacias del globalismo, respuestas a la globalización. Paidós Estado y Sociedad.

Blowfield, M. y Murray, A. (2008). Corporate responsibility: A critical introduction. Oxford University Press.

Bodemer, K. (1998). "La globalización. Un concepto y sus problemas». Nueva sociedad, N. ${ }^{\circ} 156,54-71$.

BowIE, N. (1991). «New Directions in Corporate Responsibility». Business Horizons, JulyAugust, 56-65.

Bruce, M. y DALY, L. (2011). «Adding value: challenges for UK apparel supply chain management a review». Production Planning y Control: The Management of Operations, V. 22 N.o 3, 210-220.

Caves, R. (2002). «Los efectos de difusión de las multinacionales en los países en desarrollo: Los mecanismos en acción. Revista Asturiana de Economía, N. ${ }^{\circ} 23$. Obtenido de http://www.revistaasturianadeeconomia.org/raepdf/23/P7-26.pdf

Chakravarthi, R. (2004). "Globalización y movimientos migratorios». Alternativas Sur, V. 3, N.o 1, 27-36. Obtenido de http:/www.fuhem.es/media/ecosocial/ file/Cohesi\%C3\%B3n\%20Social/Inmigraci\%C3\%B3n/RAGHAVAN, \% 20 Chakravarthi,\%20Globalizaci\%C3\%B3n\%20y\%20migraciones\%20.pdf

Chen, K. (2001). "Using free association to examine the relationship between the characteristics of brand associations and brand equity». Journal of Product and Brand Management, 439-451.

Conroy, M. (2007). Branded! How the "Certification Revolution" is Transforming Global Corporations. Gabriola Islands, Canada: New Society Publishers.

Cosans, C. (2009). «Does Milton Friedman support a vigorous business ethics?». Journal of Business Ethics, 87(3), 391-399.

Costa, J. (2007). «El lado humano de la empresa». Signo y Pensamiento, 11-12.

Cuatrecasas Arbós, L. (2012). Gestión económica de la producción: Organización de la producción y dirección de operaciones. Diaz de Sántos.

De Jong, F. (1973). Multinational Firms and the Market Form. Centre National de la Recherche Scientifique .

Dean, D. (2004). «Evaluating Potential Brand Associations through Conjoint Analysis and Market Simulation». Journal of Product and Brand Management, V. 13, N. 7.

Ditty, S. (09 de 01 de 2015). europa.eu. Obtenido de https://europa.eu/eyd2015/es/ fashion-revolution/posts/europe-world-garment-textiles-and-fashion-industry

Eberhardt, P. y Olivet, C. (2012). Cuando la injusticia es negocio: Cómo las firmas de abogados,árbitros y financiadores alimentan el auge del arbitraje de inversiones. Corporate Europe Observatory y Transnational Institute en Bruselas / Amsterdam, noviembre.

ELDIARIO (8 de 10 de 2014). La UE amenazó a Ecuador con eliminar ayudas al desarrollo si no aceptaba el libre comercio. Noticia elaborada por Juan Luis Sánchez. Obtenido de http://www.eldiario.es/internacional/Europa-Ecuador-TLC-comerciocables_0_309369531.html

ELdiario (04 de 05 de 2014). Tratado de Libre Comercio UE-EE.UU.: un sueño neoliberal, una pesadilla democrática. Noticia elaborada por Laia Ortiz / Ernest Urtasun. Ob- 
tenido de http://www.eldiario.es/zonacritica/Tratado-Libre-Comercio-UE-EEUUdemocratica_6_255884425.html

Elpaís (02 de 11 de 2014). El cambio climático amenaza con impactos irreversibles. Noticia elaborada por Miguel Ángel Criado. Obtenido de http://elpais.com/elpais/2014/11/02/ ciencia/1414927955_896799.html

Elpaís (07 de 07 de 2015). La batalla comercial en el Pacífico acerca a Estados Unidos y Vietnam. Noticia elaborada por Pablo Ximénez de Sandoval. Obtenido de http://internacional.elpais.com/internacional/2015/07/07/actualidad/1436302833_078740. html

Escalonilla, F. (2010). «Las deslocalizaciones internacionales. una visión desde la economía crítica/Internacional relocation. A view from critique economics». Cuadernos de Relaciones Laborales, 28(1), 87-130.

Fajnzylber, F. (2006). Una visión renovadora del desarrollo de América Latina. Naciones Unidas.

Farhoomand, A., y Lovelock, P. (2001). Global e-Commerce. Singapore: Text and Cases, Prentice Hall.

Fernández Sánchez, E., Montes Peón, J.M. y Vázquez Ordás, C.J. (2010). «Los recursos intangibles como factores de competitividad de la empresa». Dirección y Organización, N.o 20, 83-98.

Folkes, V. y Kammis, M. (1999). "Effects of information about firms'ethical and unethical actions on consumers'attitudes». Journal of consumer psycology, 8 (3), 243-259.

Forética (2015). Informe Forética sobre el estado de la RSE en España. Forética. Obtenido de http://foretica.org/informe_foretica_2015.pdf

Francés Gómez, P. (2005). Responsabilidad social de las empresas:fundamentos y enfoque de la gestión responsable. Madrid: Cuaderno1; Forética P.9.

Frederick (1994). «From CSR1 to CSR2». The maturing of business and society thought. Business and Society, 150-164.

Friedman (1966). Capitalismo y libertad. Madrid: Ediciones Rialp.

Gallagher, S. (2005). "A strategic response to Friedman's critique of business ethics». The Journal of business strategy, V.26 Iss: 6, 55-60.

García Rodríguez, J.M. (1997). "Las ventajas de disponer de una marca fuerte en los mercados actuales». Investigaciones Europeas de Dirección y Economía de Empresa, V. 3, N.o 3, 93-107.

GARCía, F. (2012). Responsabilidad social corporativa: teoría y práctica. Esic.

Giner, A. (2011). "Las empresas transnacionales y los Derechos Humanos». Lan Harremanak. Revista de Relaciones Laborales, 19, 67-87.

Gotzsche, P.C. (12 de 09 de 2014). «Las farmacéuticas extorsionan a los gobiernos.» (F. Sánchez, entrevistador) Obtenido de http://www.lamarea.com/2014/09/12/peterc-gotzsche-las-farmaceuticas-extorsionan-los-gobiernos-con-tecnicas-mafiosas/

Grant, R. (1991). «The resource-based theory of competitive advantages: implications for strategy formulation». California Management Review, V. 34, 114-135.

Harold Varmus (20 de 08 de 2015). No nos vamos a librar del cáncer, pero podemos reducirlo en un 50\%. (D. Mediavilla, Entrevistador, y Elpaís.com, Editor) Jerusalen. Obtenido de http://elpais.com/elpais/2015/08/19/ciencia/1440021437_708252.html

Hernández Zubizarreta, J. (2009). Las empresas transnacionales frente a los derechos humanos: Historia de una asimetría normativa. Bilbao: Hegoa.

Hernández Zubizarreta, J., y Ramiro, P. (20 de 11 de 2015). La Marea. Obtenido de http://www.lamarea.com/2015/11/20/inditex-y-la-responsabilidad-solidaria/ 
Heuskel y Costa (1999). «Estrategia en la era de la desintegración». Harvard Deusto Business Review, Nov, 36-45.

Hitt, M., Ireland , R. y Hoskisson, R. (2012). Strategic management cases: competitiveness and globalization. Cengage Learning.

Holt, B., John, A., Quelch, A., Earl, y Tylor, L. (2004). «Como compiten las marcas globales». Harvard Deusto Business Review, 6. Obtenido de http://insight.ipae.edu.pe/ media/contents/articulos/file/000277000\%201334674329.pdf

Horel, S. (08 de 2015). Gestión y control de la cadena de valor dentro del sector textil en paises en vías de desarrollo, hacia los limites de la logistica y el outsourcing: Ética o Estética. Documentación propia extraida de un analisis DELPHI/entrevista al autor. (A. Luque, Entrevistador)

Human Rights Watch (12 de 03 de 2015). Camboya: Trabajadores de la industria de la confección están desprotegidos. Obtenido de http://www.hrw.org/es/news/2015/03/11/ camboya-trabajadores-de-la-industria-de-la-confeccion-estan-desprotegidos

Hwang, H. y Seruga, J. (2011). An intelligent supply chain management system to enhance collaboration in textile industry. nternational Journal of u-and e-Service, Science and Technology, 4(4), 47-62.

Iglesias, V. (10 de 2015). "Las vías latinoamericanas del desarrollo». Le Monde Diplomatique, N. ${ }^{\circ} 240,2$.

Kelley, C., Mohtadib, S., Canec, M., Seagerc, R. y Kushnirc, Y. (2015). «Climate change in the Fertile Crescent and implications of the recent Syrian drought». PNAS. V. 112, N.o 1, 1. Obtenido de http://www.pnas.org/content/112/11/3241.full

Kumar, S., y Arbi, A. (2008). «Outsourcing strategies for apparel manufacture: a case study». Journal of Manufacturing Technology Management, V.19, N. ${ }^{\circ}$ 1, 73-91.

Lee , D. y McKenzie, R. (1994). Corporate failure as a means to corporate responsibility. Journal of Business Ethics 13 (12), 969-978.

Lobeto, J. (2014). «¿Cómo son los lobbies en Europa?». ZoomPolitico N. o 22. Obtenido de http://www.almendron.com/tribuna/wp-content/uploads/zoomPol22.pdf

Locke, R. (2013). The promise and limits of private power: Promoting labor standards in a global economy. Cambridge University Press.

Low, G.S. y LAMB, J.C. (2000). The measurement and dimensionality of brand associations. Journal of Product y Brand Management, 9, 6, 350-368.

Lozano, J. (07 de 01 de 1999). Ética y empresa. Madrid: Trotta. Obtenido de http:// www.josepmlozano.cat/Bloc0/PersonaEmpresaySociedad/tabid/218/EntryId/1345/ Los-valores-en-una-sociedad-pluralista.aspx

Luchs, M., Naylor, R., Irwin, J. y Raghunathan, R. (2010). «The sustainability liability: Potential negative effects of ethicality on product preference». Journal of Marketing, 74(5), 18-31. Journal of Marketing, 74(5), 18-31.

MaAK, T. (2009). "The Cosmopolitical Corporation». Journal of Business Ethics, N.o 84, 361-372.

MacCarthy, B. y Jayarathne, P. (2012). «Sustainable collaborative supply networks in the international clothing industry: a comparative analysis of two retailers». Production Planning y Control, V. 23, N.o 4, 252-268.

Malem Seña, J. (2002). La corrupción. Aspectos éticos, económicos, politicos y jurídicos. Barcelona: Gedisa.

Matten, D. y Moon, J. (2008). ««Implicit» and «explicit» CSR: A conceptual framework for a comparative understanding of corporate social responsibility». Academy of management Review, 33(2), 404-424. 
MCAleER, S. (2003). «Friedman's stockholder theory of corporate moral responsibility». Teaching Business Ethics, 7(4), 437-451.

Meeran, R. (08 de 07 de 2015). Declaraciones dentro del Grupo de trabajo intergubernamental de composición abierta sobre las empresas transnacionales y otras empresas con respecto a los derechos humanos. (Ridh.org, Ed.) Obtenido de http://ridh.org/estadostienen-obligacion-y-jurisdiccion-extraterritorial-en-respeto-de-ddhh/

Morin, E. (09 de 2015). «Los dos humanismos». Le Monde Diplomatique, 2.

Mulligan, T. (1986). "A critique of Milton Friedman's essay 'the social responsibility of business is to increase its profits'». Journal of Business Ethics 5 (4), 265-269.

Muñoz, M. (2007). El enigma Chino. Madrid: Treinta años de observador, Espejo de Tinta.

Naredo, J. (1999). Desarrollo económico y deterioro ecológico. Madrid: Visor y Fundación Argentaria.

Navarro, V. (23 de 05 de 2013). Lo que no se dice sobre Bangladesh. Obtenido de vnavarro.org: http://www.vnavarro.org/?p=8939ylang=CA

Nieto de Alba, U. (1994). Economía, corrupción y ética. Cuadernos de formación veintiuno, 5.

OIT (2005). Eighth Survey on the effect given to the Tripartite Declaration of Principles concerning Multinational Enterprises and Social Policy. Obtenido de OIT GB.294/ MNE/1/1: http://www.ilo.org/public/english/standards/relm/gb/docs/gb294/index. htm\#ESP

Oliván, F. (08 de 2015). «Gestión y control de la cadena de valor dentro del sector textil en países en vías de desarrollo, hacia los límites de la logística y el outsourcing: Ética o Estética. Documentación propia extraida de un analisis DELPHI/entrevista al autor. (A. Luque, Entrevistador)

Ordaz, P. (11 de 05 de 2014). La ciudad envenenada de Italia. Obtenido de Elpaís.com: http://internacional.elpais.com/internacional/2014/05/10/ actualidad/1399748074_428632.html

Ostas, D. (2001). Deconstructing corporate social responsibility: insights from legal and economic theory. American Business Law Journal, 38(2), 261-299.

Pearce, F. y Toombs, S. (1998). Toxic Capitalism: Corporate crime and the chemical industry. Aldershot: Ashgate, 1 .

Porter, M. y Kramer, M. (01 de 2011). Creating Shared Value. How to reinvent capitalism and unleash a wave of innovation and growth. Harvard Business Review.

Pozen, R. (2013). Productividad extrema : potencia tus resultados y reduce horas de trabajo. Gestión 2000.

Ramonet, I. (09 de 2009). Mafias farmacéuticas. Le Monde Diplomatique. N. ¹67, 1.

Ramonet, I. (2001). Impacto de la globalización en los países en desarrollo. Revista Memoria N. ${ }^{\circ} 143$.

Robbins, S. y Stobaugh, R. (1973). Money in the Multinational Enterprise: A Study of Financial policy. New York: Basic Books, pag. 10, del año 1973.

Rodil, O. y Menezes, V. (2012). La crisis financiera global en perspectiva: génesis y factores determinantes. Revista de Economia Mundial 31, 222-223. Obtenido de http:// rabida.uhu.es/dspace/bitstream/handle/10272/6011/La_crisis_financiera_global. pdf?sequence $=2$

Rodríguez, G. (1999 ). Derecho internacional y globalización V.11. Isonomía.

Rojas, M., M'Zali, B., Turcotte, M. y Cooli, M. (2006). Corporate social responsibility, the stakeholder approach and beyond: in search of theoretical explanations for "doing well 
while doing good». San Luis Potosí: Ponencia presentada en el X Congreso Anual de la Academia de Ciencias Administrativas A.C. (ACACIA).

Rulli , M. y Justo, J. (2012). Guía de derechos humanos para empresas. Buenos Aires: Programa Naciones Unidas para el Desarrollo-PNUD; Red Argentina Pacto Global. Obtenido de http://business-humanrights.org/sites/default/files/media/documents/ empresas-derechos-humanos-ruggie.pdf

Ryder, G. (27 de 02 de 2015). Socialeurope.eu. Obtenido de http://www.socialeurope. eu/2015/02/labor-in-the-age-of-robots/

SÁnChez BARrilao, J. (2004). Sobre la constitución normativa y la globalización. Revista de la Facultad de Derecho de la Universidad de Granada N.o7.

SchneIder, H. (06 de 2011). La evolución de la RSE . (KPMG, Ed.) Obtenido de https:// www.kpmg.com/CL/es/IssuesAndInsights/edition/kpmgway/0506/trend/2.html

Server, R. y Villalonga, I. (2005). La responsabilidad social corporativa y su gestión integrada. Revista de Economía Pública, Social y Cooperativa, N. o 53, 137-161.

Sojo Calvo, F. (2012). Evolución y mejora en la competitividad de las empresas del sector textil-confección. Economía industrial, (385), 39-46.

Spendeler, L. (07 de 2015). Gestión y control de la cadena de valor dentro del sector textil en países en vías de desarrollo, hacia los límites de la logística y el outsourcing: Ética o Estética. Documentación propia extraida de un analisis DELPHI/entrevista al autor. (A. Luque, Entrevistador).

Standing, G. (2013). El Precariado: Una nueva clase social. Pasado y presente.

Stephen Hawking (09 de 10 de 2015). Elconfidencial.com. Stephen Hawking: La tecnología está aumentando la desigualdad en el mundo. Obtenido a través de http://www.elconfidencial.com/tecnologia/2015-10-09/stephen-hawking-la-tecnologia-esta-aumentando-ladesigualdad-en-el-mundo_1053150/

Su, J. (2013). «Strategic sourcing in the textile and apparel industry». Industrial Management + Data Systems, 113(1), 23-38.

Teitelbaum, A. (2010). «Los tratados internacionales, regionales, subregionales y bilaterales de libre comercio". CETIM. Cuaderno crítico N. ${ }^{\circ}$ 7. Obtenido de http://cetim.ch/ es/publications_cahiers.php

Teitelbaum, A. (07 de 2015). Gestión y control de la cadena de valor dentro del sector textil en países en vias de desarrollo, hacia los limites de la logística y el outsourcing: Ética o Estética. Documentación propia extraida de un analisis DELPHI/entrevista al autor. (A. Luque, Entrevistador)

Tом Boyd (09 de 10 de 2014). Tom Boyd (Clarks): «La gran distribución ha introducido en la mente del consumidor que los zapatos son moda» (S. Riera, Entrevistador) Internet. Obtenido de http://www.modaes.es/back-stage/20141009/tom-boyd-clarksla-gran-distribucion-ha-introducido-en-la-mente-del-consumidor-que-los-zapatosson-moda.html

Torres, E. (2006). The corporate responsibility. En Del Val, M., Sánchez, Y. and García, C. (Eds.). Economy, entrepreneurship, science and society in the XXI century, Alcalá de Henares: Universidad de Alcalá.

Van Harten, G. (2010). «Five Justifications for Investment Treaties». A Critical Discussion, Trade, Law y Development 2:1, 5. Obtenido de http://www.tradelawdevelopment.com/index.php/tld/article/view/2\%281\%29\%20TL\%26D\%2019\%20 $\% 282010 \% 29$

Verge, P. y Dufour , S. (2002). «Entreprises transnationales et droits du travail». Relations Insustrielles, V. 75, N. ${ }^{\circ} 1,12-47$. 
Vidal, S. y Estefanía, J. (2002). «La cruzada contra los paraísos fiscales: ultimátum de la OCDE. Otra sensibilidad sobre los paraísos fiscales». Escritura pública, (13), 30-33. Obtenido de http://www.notariado.org/liferay/c/document_library/get_file?folderId= 12092 yname=DLFE-11505.pdf

Vintró SÁNChez, C. (2010). «La responsabilidad social corporativa en la empresa». Técnica Industrial, N. ${ }^{\circ} 285,66-71$.

Weber, M. (2008). «The Business Case for Corporate Social Responsibility: A Companylevel Measurement Approach for CSR». European Management Journal, 26(4), $247-$ 261.

Werner, K. y Weiss, H. (2006). El libro negro de las marcas. Buenos Aires: Editorial Sudamericana.

White, K. (2012). "Belief in a just world: consumer intentions and behaviors toward ethical products». Journal of Marketing, V.76, N. ${ }^{\circ} 1,103-118$.

Yoo, B., Donthu, N. y Lee, S. (2000). "An examination of selected marketing mix elements and Brand equity». Journal of Academy of Marketing Science, V. 28, N. ${ }^{2}$ 2, 195 211.

Zabalo, P. (2006). «El papel de las multinacionales en la economía globalizada». Pueblos, N. ${ }^{\circ}$, 5-9.

Zамова Савот, F. (2012). La responsabilidad de las empresas multinacionales por violaciones de los derechos humanos: práctica reciente. Papeles El tiempo de los derechos N.o 1. Obtenido de http://hdl.handle.net/10234/95195

Ziegler, J. (2013). Los nuevos amos del mundo: Y la lucha de aquellos que se resisten a dejarse engullir por la globalización. Destino. 